\title{
إدارة حفظ وصيانة المجموعات
}

\section{د/ خالد المزاحي \\ كبير أخصائي الترميم والصيانة \\ مكتبة الاسكندرية \\ mezahy@yahoo.com}

تناولت هذه الدراسة موضوعًا من الموضوعات الحيوية في قطاع المكتبات والمعلومات، وهو الحفاظ على التراث الثقافي المعرفي المكتظ بالمكتبات؛ فالمكتبات هي التي تقوم بعمليات المات

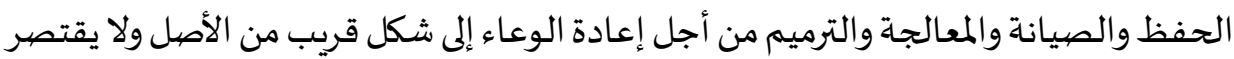

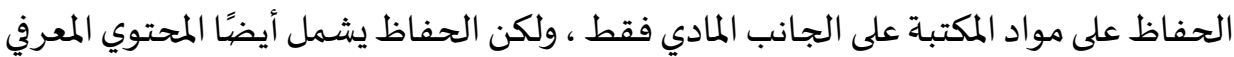

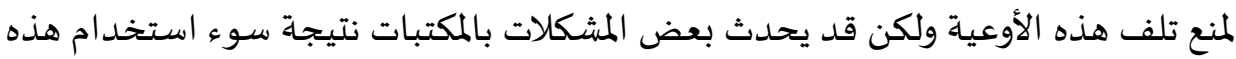

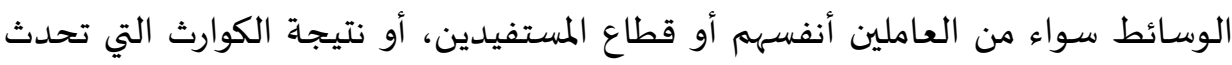

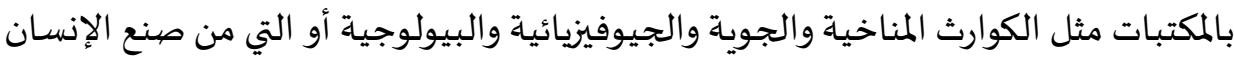
مثل السرقة وإبادة الكتب والتدمير وغيرها. ثم تناولت الدراسة موضيوعًا أخر هو عمليات التعقيم والتبخير والذي كان يتما بأنما بأساليب

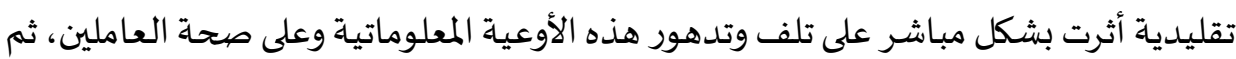

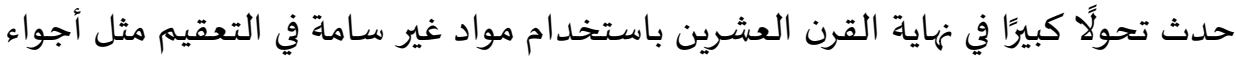
الأكسجين المنخفض، وعمليات التجميد من أجل قتل الحشرات والميكروبات العالقة بهذه ميده

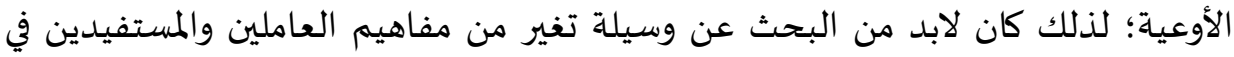

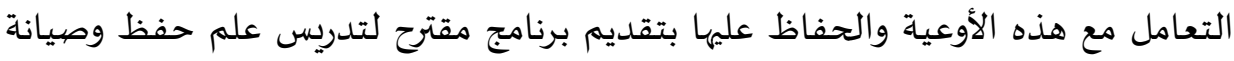
الأوعية المكتبية الثقافية والتراثية. الكلمات المفتاحية: الحفظ - الصيانة - التعقيم - إدارة الكوارث 


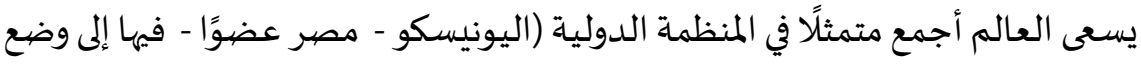
الاتفاقيات والتوصيات لحماية التراث الثقافي، ويقتضي ذلك إقرار نصوص تشريعية مناسبة تحدد طبيعة الحماية التي ينبغي توافرها وتحديد نطاقها، وتبين التدابير التي تكفل توفير هذه

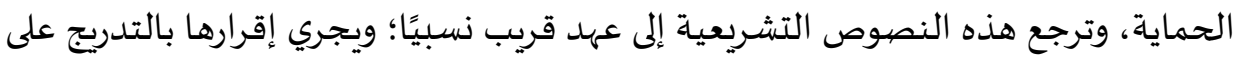
المستويين :الدولي والوطني .

لقد حدد اليونسكو المبادئ والمعايير التي ينبغي أن تنظم حماية التراث الثقافي، إذ يلاحظ

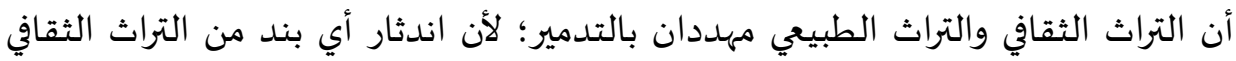

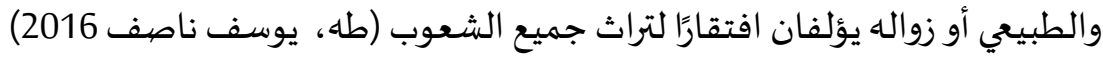
وفي هذا البحث يتم الحديث عن حفظ وصيانة أوعية المعلومات التي تعد ذاكرة الأمة،

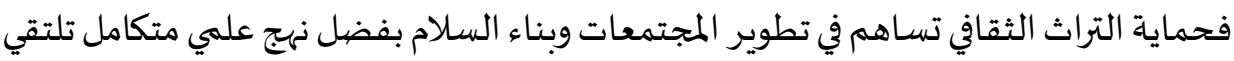

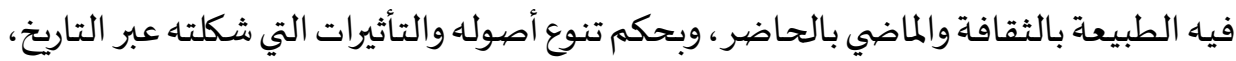
يرتدي التراث الثقافي أشكالًا مختلفة ملموسة وغير مادية، إلا أن التراث الثقافي باتهات يفقد واتد معناه

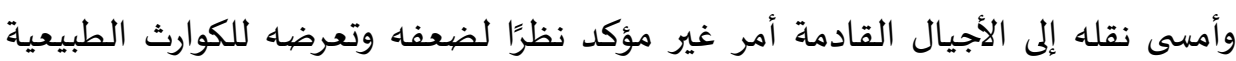

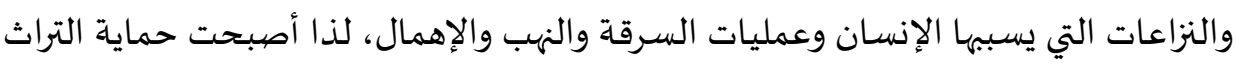

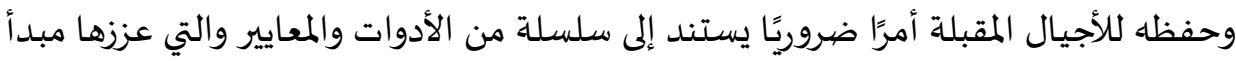
المسئولية التضامنية منذ ظهور مفهوم التراث العالمي.

(As cited by unesco2016)

وقد شهد القرن العشرون مولد علمًا جديدًا يخدم -بطريقة مباشرة -التراث الإنساني

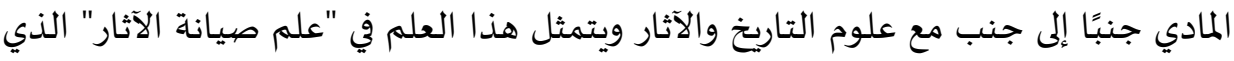

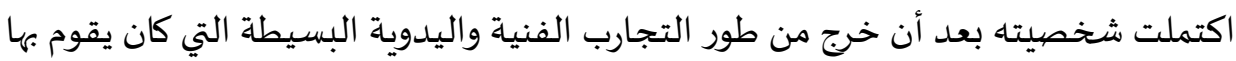

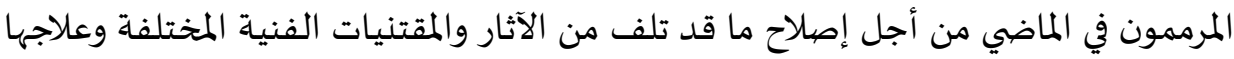

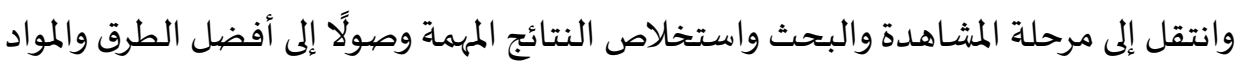


الكيماوية التي يجب استخدامها في علاج الآثار التي تعرضت للتلف وصيانتها، وتوفير الظروف

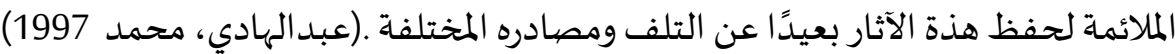

\section{1/ مسؤولية الحفاظ على الأوعية الثقافية}

تقع مسؤولية المحافظة على مجموعات المكتبة على جميع العاملين، وعلى الرغم من قيام أخصائي صيانة الأوعية بتقديم المشورة وتنفيذ المهام المناطة بهاء في هذا المجال، فإن مسؤولية المحافظة على مقتنيات المكتبة يشترك فيها جميع الموظفين، بمن فيهم مدير المكتبة، كما ينبغي عليهم جميعًا تطبيق إجراءات المحافظة على المجموعات ودعمها ومساندتها. وينبغي على المسؤولين في إدارة المكتبة، وكذلك المسؤولين عن صيانة مبانيها على المستويين الداخلي والخارجي، العمل والتعاون عن قُرب مع زملاهيهم في المحافظة على المقتنيات. وينبغي أن يأخذ القائمون على عملية الحفظ على مواد المكتبة بعين الاعتبار البيئة

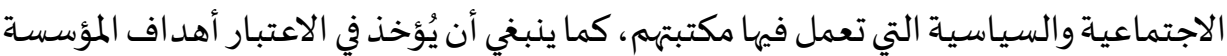
وسياسات الاقتناء والموارد المتوفرة،كما ينبغي إعداد سياسات المحافظة على المقتنيات بالتشاور مع الإدارات المختلفة للأسباب التالية: • على أقسام التزويد والاقتناء في المكتبة أن تكون مستعدة لشراء نسخ إضافية من المواد المستخدمة بكثافة، كالمواد المرجعية، عندما تكون تكاليف ترميم هذه المواد أعلى من تكلفة

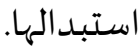
•أن يوفر قسم الفهرسة وقسم خدمات المعلومات النسخ الإضافية من الكتب والمراجع على الرفوف وليس النسخة الأصلية.

• على الأقسام التخطيط لتوفير المساحة الكافية ذات النوعية الجيدة التي يتم وضع مقتنيات المكتبة فيها كأن توضع الكتب الكبيرة بشكل أفقي والصغيرة بشكل رأسي. •ضرورة إحاطة موظفي قاعة الاطلاع بالمكتبة بأي قيود مفروضة على استخدام المواد الأصلية

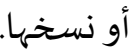


•ضرورة إتاحة الموارد اللازمة لتدريب الموظفين في مجال توفير السلامة لأنفسهم ولمواد المكتبة، وكيفية التعامل السليم معها ونقل معرفتهم المكتسبة في هذا المجال إلى المستخدمين. •سلامة المواد المعروضة أثناء إقامة معارض للأوعية التراثية، سواء أقيمت هذه المعارض داخل المكتبة أو تم استعارة هذه المواد للعرض في مؤسسات أخرى مع مراعاة الظروف المناخية. •لا يكفي فقط تَوفُّر المعرفة الفنية والعلمية لدى موظفي الحفاظ على المواد وغيرهم من الموظفين المسؤولين عن المجموعات، مهما كان مستوى خبرتهم.

بل ينبغي أيضاأن يكون لديهم المعرفة الكافية بتاريخ المجموعات، والمواد التي تتشكل منها،

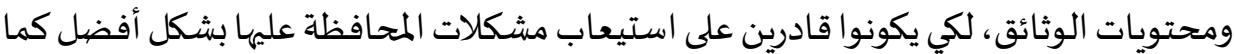
ينبغي اطلاع اختصاصي المكتبات وموظفيها على شتى المستويات، وكذلك طلاب تخصص المص المكتبات، على أهمية المحافظة على المواد ضمن الإطار العام لوظيفة المكتبة وسياستها.

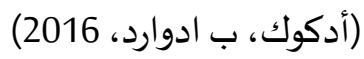

كما تقع على أختصاصي المكتبة مسئولية ضمان اتخاذ الإجراءات المناسبة لحماية

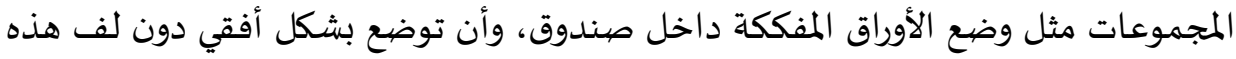

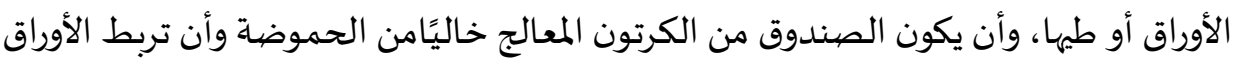

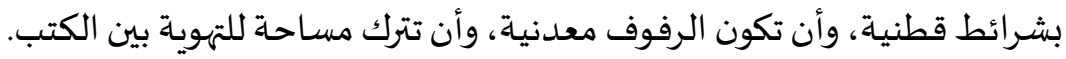
أما بالنسبة لتنظيف الكتب يتم وضع برنامج لعاملي المكتبات تحت إشراف فني

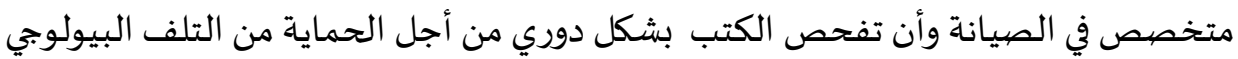
أو الكيميائي او الفيزيائي.

1/1 إدارة الحفظ

إن السبب الحقيقي لوجود المكتبة هو جمع الوثائق والمطبوعات والمخطوطات وغيرها من الأوعية الثقافية من الماضي والحاضر، وحفظها حتى تكون متاحة لكل المستفيدين . و من الضروري أن يدرك المكتبيون وكذلك المرممون أههم يتعاملون مع أشياء ذات طبيعة

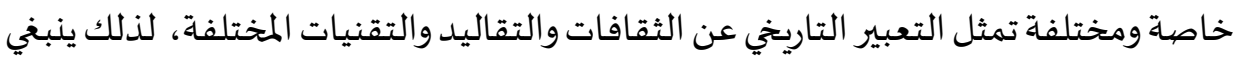


(Dureau, إجراء الترميم بحرص شـيد قدر الإمكان مع مراعاة الحفاظ على الشكل الأصليل Jeanne- marie1980)

2/1 2 2 2 اقع الحفظ

يسعي الحفظ الى تبسيط الموضوع لغير المختصين، وأن برنامج الحفظ الفعال هو نتاج للعديد من العمل اليدوي والمعرفة التقنية المتعمقة لتحقيق مهمتها في الحفاظ على المجموعات

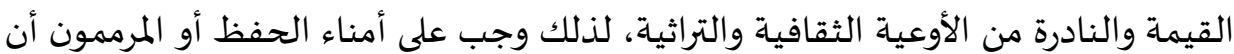

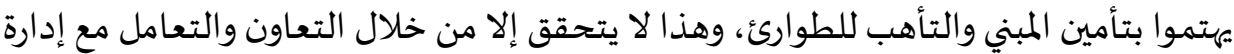

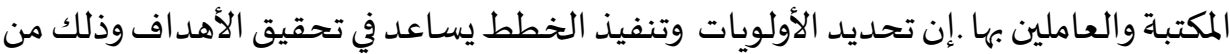
خلال المنشورات التي تصدرها Association Research Libraries.

\section{Priorities 3/1 تحديد الأهداف والأولويات}

من الواجب على المكتبة أو المؤسسة أن تدعم أهداف الحفظ والتوجهات والخطط، وأن

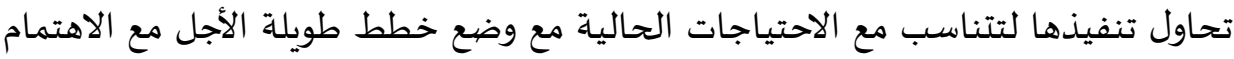
بخدمات أوسع لطلبات المستفيدين مع وجود الكتب على الرفوف، كما تركز قائمة أولويات

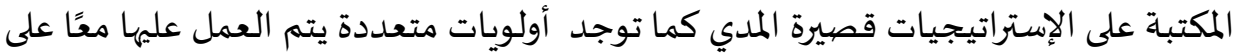
المستويين الإستراتيجيين الكلي والجزئي : الأولوية الأولى: أمن المجموعات، والتأهب للكوارث ، وهذه الأولوية سيكون لها تأثير إيجابي في

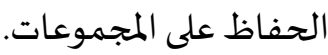

الأولوية الثانية: الحفاظ على المجموعات التالفة التي في حالة طلب من المستفيدين بما في ذلك

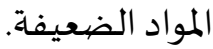
الأولوية الثالثة: الحفاظ على المجموعات المكتسبة أو المقتناة حديثًا والتي ليست في حالة مادية

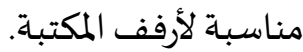
الأولوية الر ابعة: الحفاظ على المجموعات التالفة وليس عليها طلب من المستفيدين بما في

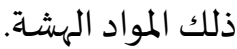


الأولوية الخامسـة: الحفاظ على المجموعات المكتسبة حديثًا في شروط مناسبة. وكخطوة أولى يجب أن تركز أولويات الحفظ على الإسترتيجيات طويلة المدي، أي الإستراتيجيات التي من المحتمل أن تحقق مكسب أكبر مقابل التكلفة، كإستراتيجيات وقائية

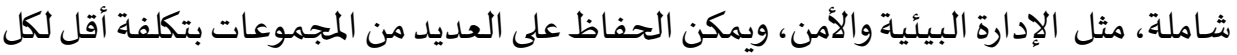

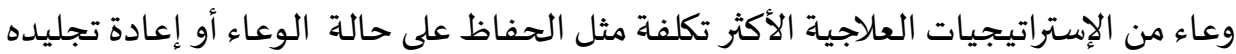
أو تنظيفه أو تهيئته (soete, George 2013)

\section{4/1 - طبيعة المبادئ والأهداف}

تمثل المبادئ نهجًا عامًا لتحديد طبيعة وأهداف حفظ وترميم مقتنيات المكتبة وبالتالي فهى لا تهدف إلى إعطاء صورة كاملة عن الأساليب والإجراءات، ولكنها ترغب في إثبات سلوك

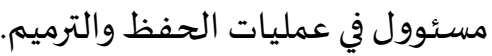

يجب تحديد الوسائل التقنية؛ لتحقيق أهداف الحفظ والترميم بشكل مشترك من قِبل

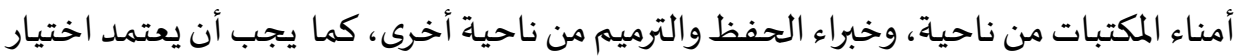

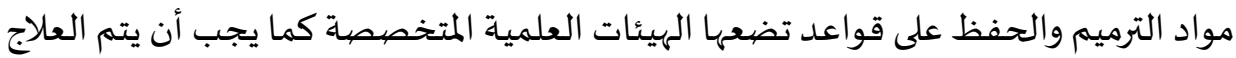
تحت إشراف خبراء مدربين تدريبًا جيدًا.

إن المخاطر التي تهدد المجموعات معروفة جيدًا لأختصاصيي المكتبات، لكن في الغالب لا يعلنون عنها ويعرفون عواقبها في المستقبل، والغرض من هذه المبادئ هو تشجيع المسئولين عن

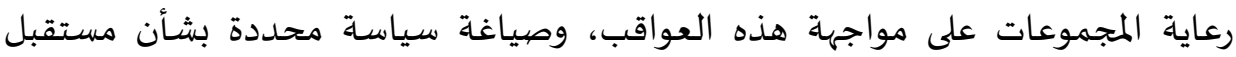

المجموعات، بمساعدة خبرائها العلميين والفنيين.(Dureau, Jeanne lbid)

Cost, Donation \& Funds 5/1 التكاليف والمنح والهبات

يحتاج المسؤول عن الحفاظ معرفة التكلفة الفعلية لصيانة المجموعات حتى يمكنهم

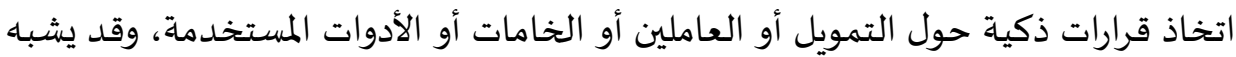

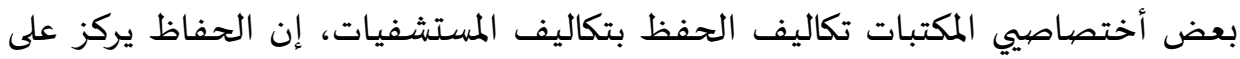

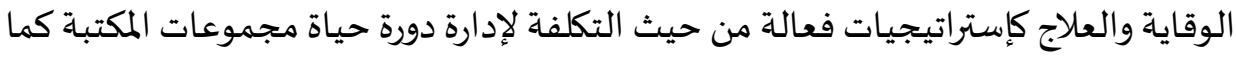


تتطلب الإسترتيجيات بعيدة المدي أوالكلية مثل الإدارة البيئية والأمن تكلفة أولية عالية، ولكنها

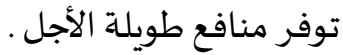

تحديد تكاليف الحفظ ينطوي على النظر في عدد من المتغيرات التي قد تختلف اختلافًا كبيرًا من مكتبة إلى أخرى، اعتمادًا على عدد المجموعات وحجمها وحالتها،والخامات والميزانية المقترحة وشروط الحفظ الجيد، وقد تقوم بعض المكتبات بحساب التكلفة حسب عدد الصفحات؛ للمساعدة في التعرف على تكاليف الحفظ وذلك فيما يتعلق على المستوى الجزئي. وقد تلجأ بعض المكتبات إلى الاستعانة بعض الطلاب الجامعيين كمتطوعين للعمل بأجر رمزي في عمليات الحفظ والصيانة، مما قد يقلل من التكاليف، كما يتطلب الحفظ كادرًا من العاملين المهرة والمدربين بشكل مناسب للإشراف على هؤلاء الطلاب، وقد تلجأ بعض المكتبات الكبرى إلى الاستعانة بشركات متخصصية في التجليد (وقد شـاهد الباحث- عندما كان

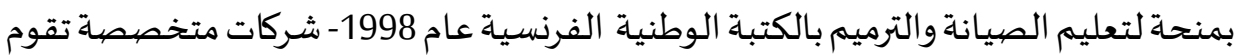
بتجليد الكتب الجديدة بمواصفات حُددت من قبل المكتبة الوطنية الفرنسية لإعادة تجليد

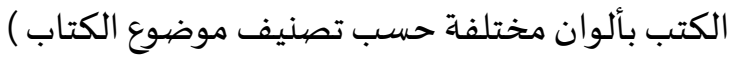
تنفق الولايات المتحدة الأمريكية أكثر من 92 مليون دولار على الحفظ سنويًا وحسب

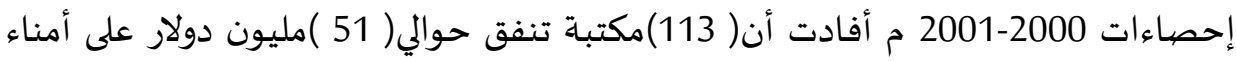
الحفظ بتكلفة إجمالية متوسطة تقترب من(

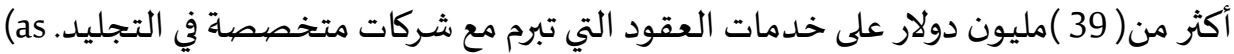
cited by soete, jeorge)

يري الباحث " نظرًا لارتفاع تكاليف خامات وأدوات الحفاظ على الأوعية الثقافية؛ فقد

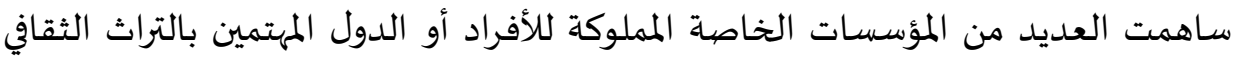

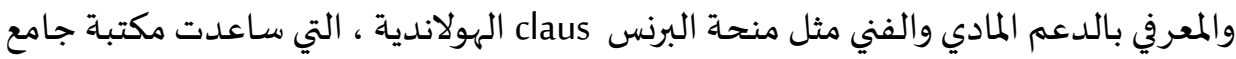

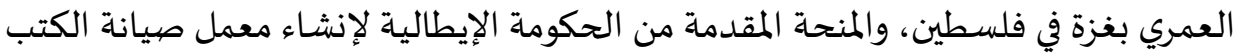

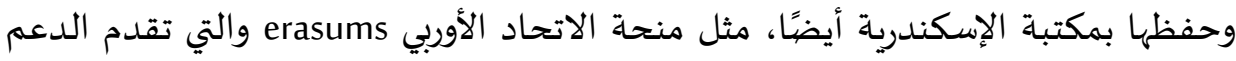

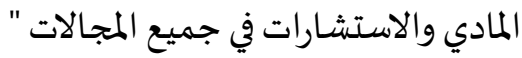


يوفر الحفظ فُرصيًا للتمويل مع تزايد أهمية المنح وحملات العطاء السنوية وإدارة الوقف

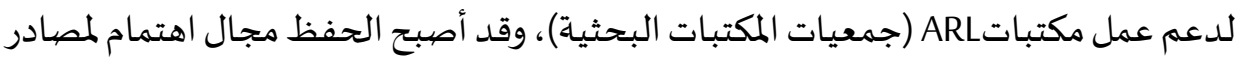

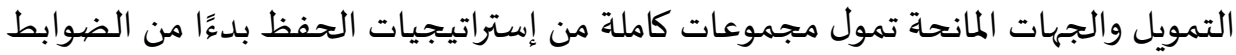
البيئية حتى الميكروفيلم وعلاجات الحفظ وتقوم بعض وكالات التمويل بتشجيع ودعم المناهج

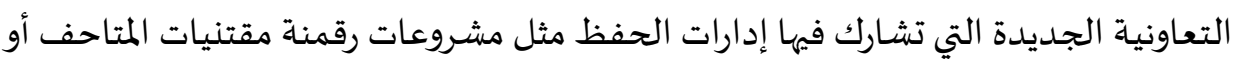
(soete, jeorge lbid). المكتبات

\section{6/1 6عربف الحفاظ Preservation}

مصطلح الحفاظ يعني عملية تشمل كافة الاعتبارات الإدارية والمالية، وإجراءات

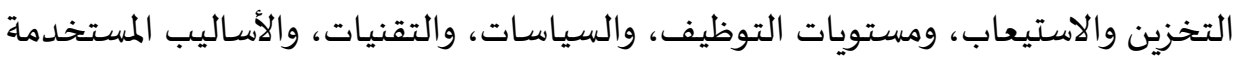

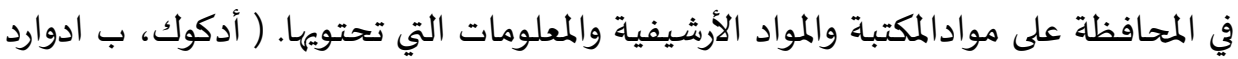

إدارة الحفاظ تعني بالتدريب وفهم النظريات والمعرفة والممارسة والتخصص الدقيق

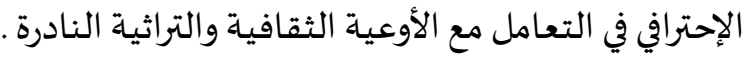

إن التعريفات والمصطلحات في حالة تغير مستمر لعدة سنوات؛ فتري جمعية أمناء

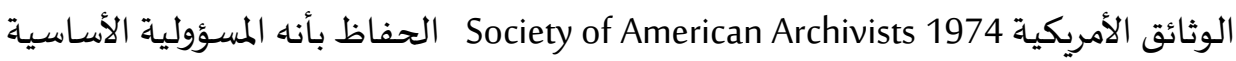
في توفير التسهيلات الكافية لحماية الوثائق والسجلات والمخطوطات وصياتيانتها، وهي أيضًا إجراءات محددة فردية أو جماعية لصيانة الأوعية الثقافية وترميمها .

أما في عام 1992 فتري نفس الجمعية بأن مصطلح الحفاظ هو مجمل العمليات التي تنطوي على تثبيت الوثائق والمستندات وحفظها من التلف ونقل المعلومات إلى وسيلة أخري مثل

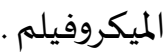

أما المجلس الاستشاري الوطني للحفظ National Conservation Advisory Council

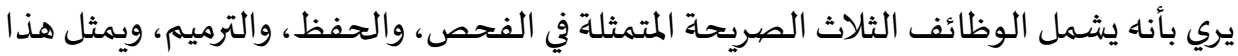

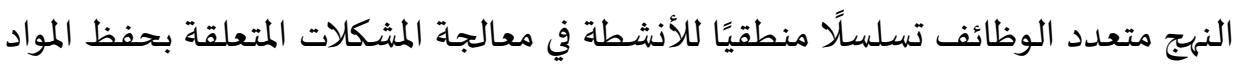
الثقافية، حيث تعالج بعض برامج الحفظ العديد من المشكلات التالية مثل : التخزين، 
الإستخدام، المناولة، صيانة المجموعات، إعادة النسخ، المعالجات، التأهب للكوارث، تقييم

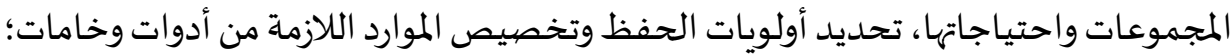

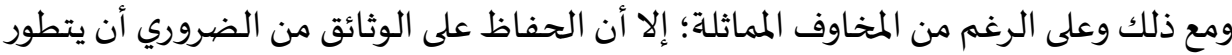
وفقًا لبعض البرامج المختلفة . (lynn, Mary 1993) وترى جمعية المكتبات الأمريكية أن هناك عدة أسباب تجعلنا نُفعل مفهوم الحفاظ على

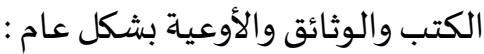
1- يعزز الحفاظ مبدأ الإتاحة، أي أن تكون المجموعات متاحة للجميع أو المستفيدين دون أية تفرقة، أي المساواة في مجال المعرفة .

2- الحفاظ على المجموعات القديمة أو النادرة خاصة في العصر الرقمي والتي ليس لها نسخ

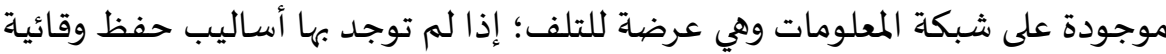
والرقمنة ليست مثل الطبعة الأصلية . 3- الحفاظ على المجموعات المكتبية الحالية والمستقبلية يساعد على جذب الطلاب والمستفيدين .

4- عندما تتلف المجموعات المطبوعة بالمكتبة بشكل سريع يصبح استبدالها صعبًا أو

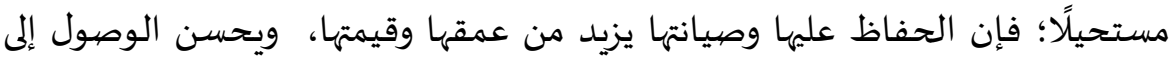
مجموعة واسعة من الموضوعات . 5- من خلال الحفاظ على المواد الأصلية والنادرة داخل المكتبات نستطيع أن نحافظ على

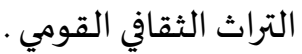

6- من خلال الحفاظ على المواد الأصلية والنادرة تستطيع المكتبة أن تشتري مواد جديدة . 7- الحفاظ على المجموعات القديمة يسلط الضوء على الماضي، ويصل الحاضر، ويساعد على

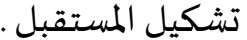

8- الحفاظ على المجموعات من خلال تقديم خدمات الإعارة؛ وبذلك تضهمن المكتبة تداولًا

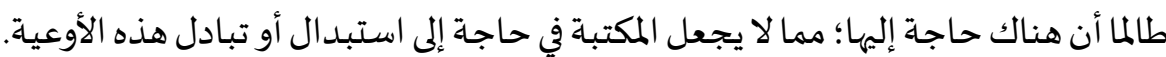


9- تحتفظ المكتبات الكبرى أو المؤسسات العلمية بأوعية ثقافية وتراثية ووثائق لا تقدر بثمن. 10-الحفاظ يعزز مبدأ الثقافة الخضراء من خلال السماح لكل وعاء أن يظل متداولًا طالما كانت هناك حاجة لذلك - وبالتالي إطالة عمره و القضاء على الحاجة للاستبدال. (as cited by, ALA) الثقافة الخضراء :تعني الانسجام بين الإنسان والطبيعة أو خلق تكيف بشري مع البيئة و جميع النباتات الخضراء رمز للثقافة (Green culture, 2011)

يشير الحفظ إلي حماية المقتنيات الثقافية عن طريق تقليل استخدام المواد الكيماوية،

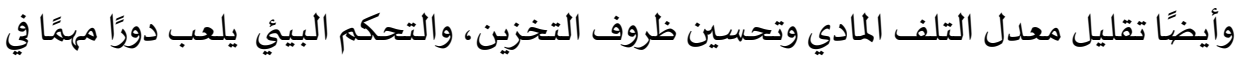
ذلك؛ فالهدف هو إطالة عمر المواد الثقافية.(Aiccom 2015 )

ويرى الباحث أن الحفظ هو عملية ملاحظة مبكرة تؤخر من تدهور الأوعية الثقافية

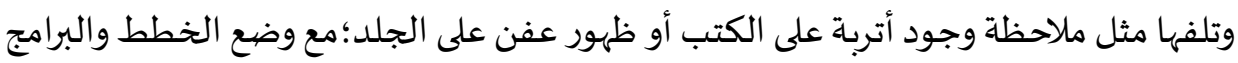

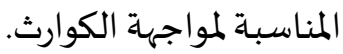

\section{Restoration 7/1 تعريف الترميم}

يذكرد/ الحلوجي ( الحلوجي، عبدالستار 1989) أن ميزانية دار الحكمة والتي أنشأها

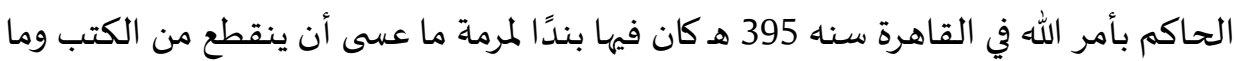
عساه أن يسقط من ورقها. وتري الجمعية الأمريكية للمكتبات أن الترميم هو فن إعادة الكتاب، أو الشيء، أو العنصر المراد ترميمه في حالته الأصلية أو في شكل قريب من الأصل. (ALA, lbid) أما المعهد الأمريكي للصيانة والحفظ فيرى أن الترميم هو استعادة أو استكمال أو إعادة

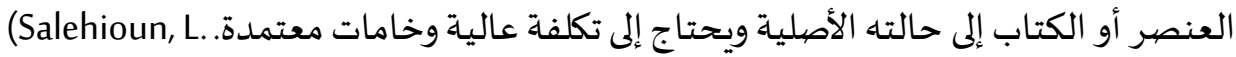
Azadi 2019)

الترميم: هوكل الإجراءات المطبقة مباشرة على عنصر واحد ومستقر؛ يتم تنفيذ هذه الإجراءات

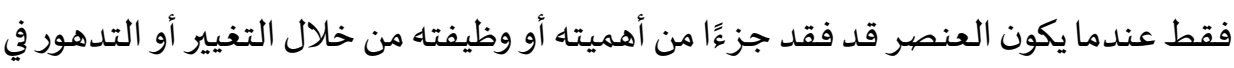
الماضي، وهي تستند إلى احترام المواد الأصلية .. (as cited by journal open edition 2019) 
أنواع الترميم

يمكن تقسيم الترميم إلى ثلاثة أنواع : الترميم اليدوي، والترميم الآلي، والترميم الحراري

الترميم اليدوي: هو عملية يدوية خاصة تتصل بقوة التحكم، ومهارة العمل، وجمالية التعامل مع الآثار والمخطوطات باستخدام بعض الأدوات الخاصة التي تختلف من شخص إلى إلى آخر

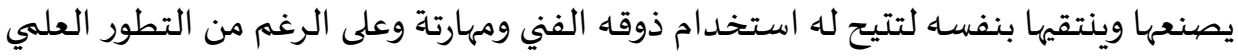

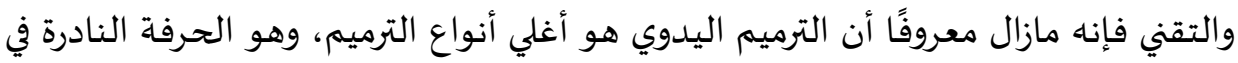

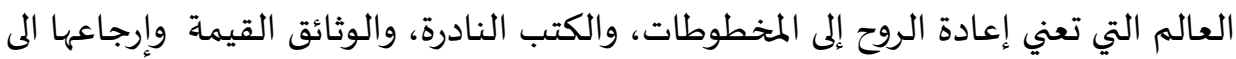
أصلها؛ فالترميم يحتاج الى صبر ودقة وخبرة عالية (سميح، منصيور 2010)

الترميم الآلي: Leaf-Casting باستخدام الألياف الورقية، ويستعمل في أضيق الحدود بالنسبة

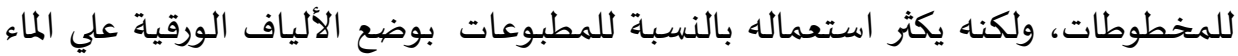
وتثبيت الصفحات علي الجهاز ثم يتم انتشار الألياف وتوزيعهاعلي سطح الماء، ثم يتم شفط الماء الماء

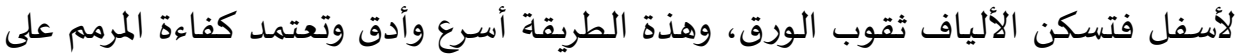
حساب كمية الألياف مع عدد الثقوب ـ (داغستاني، بسام 2002)

الترميم أو التجليد الحراري: Lamination ويطلق عليه جهاز التدعيم الحراري،وهو يستخدم للمطبوعات مثل الجرائد، والمجلات، والقصص، والكتب القديمة والتي من الصعب ترميمها

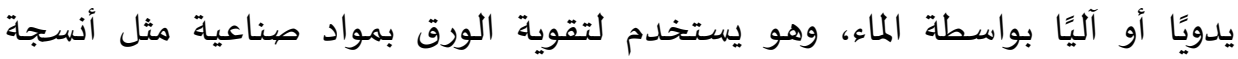
Cerex+Bifix

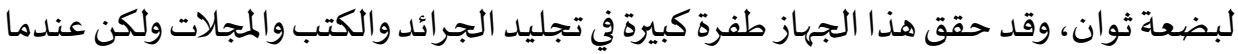
ذهب الباحث إلى فرنسا بالمكتبة الوطنية للتدريب على فنون الترميم والتجليد شـاهد العاملين

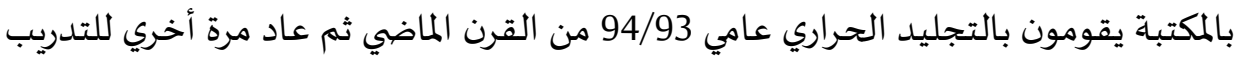

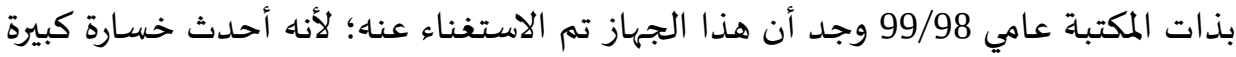

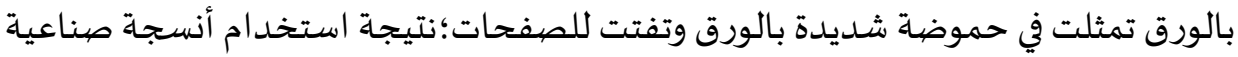
(الباحث بمكتبة فرنسا 1993) 
ولكي نتجنب بعض المخاطرفي عملية الترميم هناك بعض الشروط الواجب اتباعها: 1. الترميم يجب أن يكون محاطًا بالمنهجية العلمية الشاملة للحفاظ على الكتب أو الوثائق في بيئة صحية صالحمة .

2. ضرورة اختيار الكتب التي تحتاج إلى إنقاذ سريع أو علاج . 3. التدخل يكون في أضيق الحدود .

4. التدخل يجب أن يكون حذرًا لأنه قد يؤدي إلى بعض التلف وعمليات الترميم يفضل أن تكون مرئية .

5. الخامات والأدوات والمواد المستخدمة لابد وأن تكون مطابقة وملائمة مع المواد الأصلية،

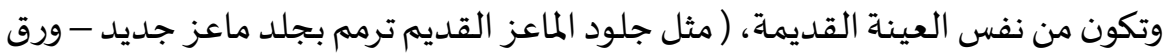
مصنع من خامات طبيعية يرمم بورق مصنع من خطوات طبيعية ) وأن تكون هذه المواد

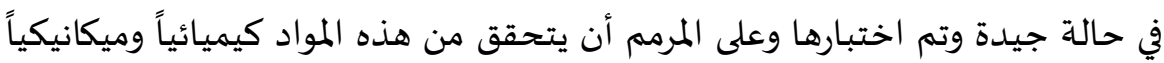

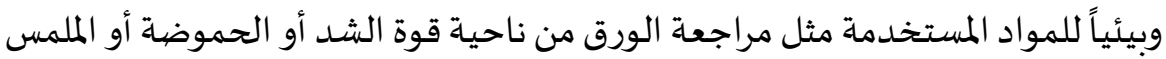
أو التصنيع .

6. التعرف على كل العناصر المستخدمة في الترميم؛ فإذا تم التحقق منها وثبت صلاحيتها تم

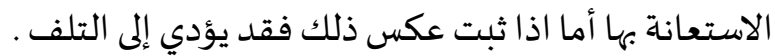

7. أن تتم عمليات الترميم بشكل أمين وشفاف وواضح للجميع، وكل عملية لابد من تسجيلها

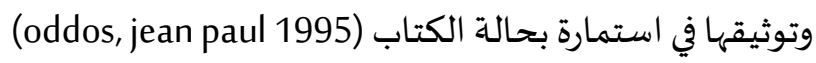
8. احترام الطرق والأساليب القديمة، فيجب على المرمم أن يحافظ على الشكل القديم

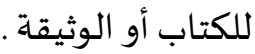

9. الترميم عملية عكسية؛ أي يمكن إزالتها عند الحاجة إذا طرأت علينا مناهج جديدة في العلاج.

10. الإخلاص والأمانة في العمل؛ فكل أنواع الترميم هي إعادة بناء المخطوط مرة أخري؛ لذلك

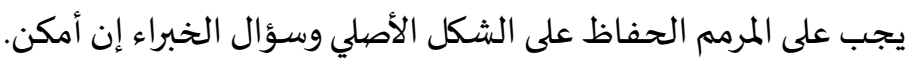


11. التوثيق وذلك بعمل استمارة يوضح بها بيانات الوثيقة، وتاريخها، ومكان وجودها،

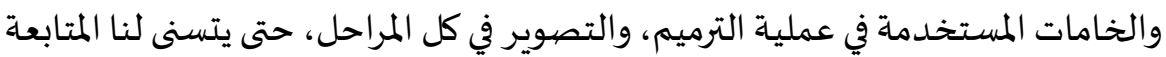
ومحاسبة المخطئ أو يكون سند علمي في عمليات التدريب للمرممين الجداد. 12. لابد من وجود مظروف أو حاوية توضع فيه أي أشياء متساقطة متعلقة بالعمل؛ حتى يمكن إعادتها إلى أصلها (Adam, Claude , 1991)

\section{8/1 تعريف الصيانة Conservation}

مهنة مخصصة للحفاظ على الممتلكات الثقافية تشمل أنشطة الحفظ، والفحص، والتوثيق، والعلاج والصيانة الوقائية ، مدعومة بالبحث والتعليم ( AIC, Ibid ) preservation, protect, and هو المصطلح الذي يحتضن ثلاث أفكار مرتبطة ACLS American Council of learned الحفظ و الحماية والإصلاح وفقًا تلائا Societies

إن الحفاظ على مواد المكتبة هي المشكلة الأكثر خطورة؛ لذلك فإن مجال الصيانة لايزال

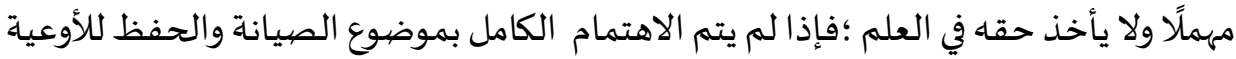

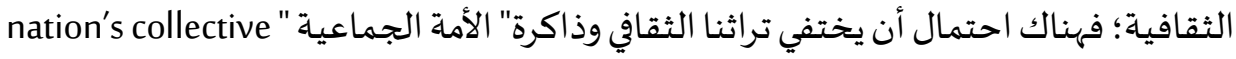

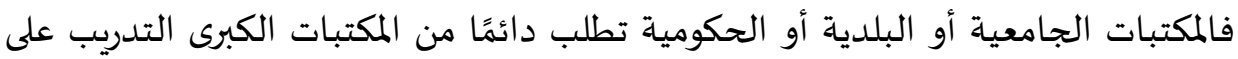
الفهرسة والتصنيف واختيار الكتب فقط وليس الصيانة أو الحفظ. الفرق بين مصطلحي الحفظ والصيانة غير واضح إلى حد ما، حيث استخدمت هذه

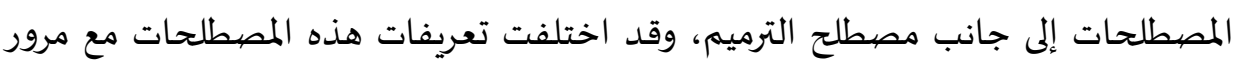
الوقت، استخدم مصطلح الحفظ منذ بداية الثمانينيات في المكتبات ومراكز المعلومات كمظلة للأنشطة التي تقلل الضرر لإطالة عمر المجموعات (NEDCC). أما مصطلح الصيانة فقد استخدم بشكل أكثر تحديدًا في المعالجة المادية للعناصر 
وتنقسم الصيانة إلى الصيانة العلاجية، والصيانة الوقائية

- أولًا: الصيانة العلاجية Conservation treatment:

وتشير إلى إصلاح عناصر محددة داخل المجموعات، يتميز العلاج عادة بفئتين عريضتين:

الاستقرار المادي (مثل إصلاح كعب الكتاب وترميم وإصلاح الأوراق) والاستقرار الكيميائي(مثل

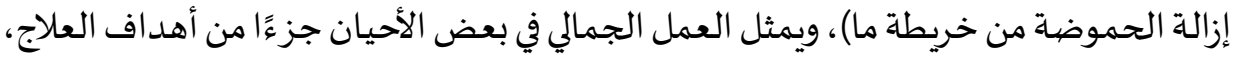

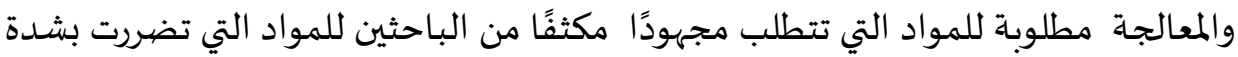
(American Philosophical Society)

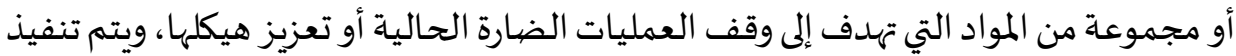
هذه الإجراءات فقط عندما تكون هذه العناصر في حالة من الهشاشـة أو التدهور، ومن أمثلة الصيانة العلاجية تعقيم الكتب، وإزالة الحموضاة من الورق وتجفيف المدواء المواد الأثرية الرطبة.

- ثانيًا: الصيانة الوقائية Preventive conservation

وهي الإجراءات والخطط التي تهدف إلى تجنب أى تدهور أو خسارة في المستقبل وتقليلها.

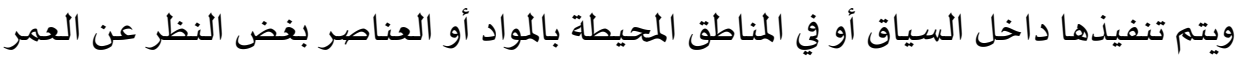

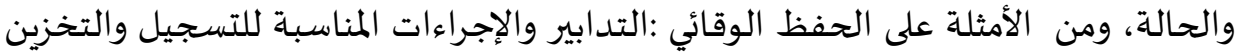

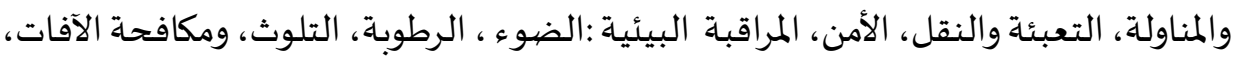

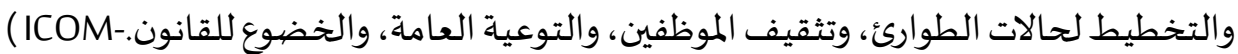
(CC 2008

وتري جمعية المكتبات الأمريكية :أن الصيانة هي عملية إصلاح ومتابعة لكل عنصر في

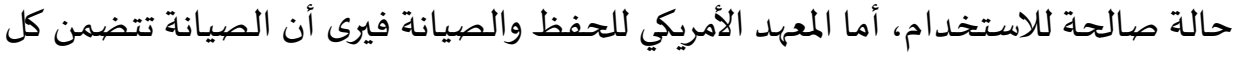
الإجراءات والشروط والتسهيلات اللازمة لصيانة هذا العمل، ولابد من بذل كل الجهود

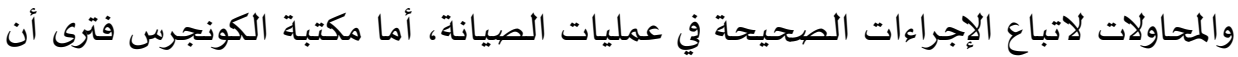

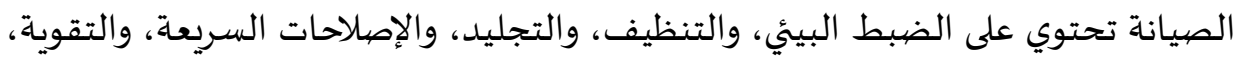

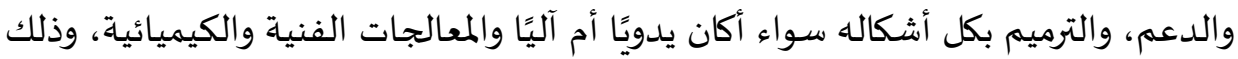
لإطالة عمر الكتب داخل المكتبة ولتقليل النفقات.(Library of Congress) 
اتخاذ قرار الصيانة يسهل علينا تحديد المجموعات التالفة في المكتبة عن طريق الفهرسة الشاملة، وتوجد أدوات شاملة لتقييم نقاط القوة والضعف مثل حقل RLG research libraries group بالصيانة) ويمكن لأختصاصيي المكتبات تحديد المواد التي ستشكل مجموعة شاملة في موضوع معين وتحتاج الى قرار صيانة البدء في عمل برنامج حفظ تعاوني شامل لهم (NEDCC, lbid)

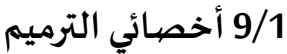

هو شخص محترف يقوم بممارسة أعمال الحفظ والصيانة من خلال تعليم متخصص وتدريب ومعرفة وخبرة لصيانة وتنفيذ جميع أنشطة الحفظ والصيانة وفقًا لقواعد أخلاقية

(moses, pearce 2005)

أما المعهد الأمريكي للأشغال التاريخية والفنية (AIC 2016) يرى بأن الذي يقوم بعملية الترميم هو الشخص الفني الذي لديه المعرفة والخبرة والقدرات الفنية والدقة والصبر لإصلاح وترميم الأعمال الفنية التي لها قيمة تاريخية أو فنية.

وغالبًا ما تكون هذه المعامل بالمكتبات عبارة عن حجرات صغيرة بها فرد أو فردين فقط مما يؤدي ذلك الى ضعف معلومات المرمم نتيجة قلة الدعاية وتداول المعلومات ويصبح المرمم في عزلة لأنهم خارج منظومة المكتبات الكبرى فلا يحدث اتصال بين المرمم والباحثين

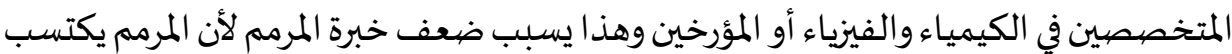

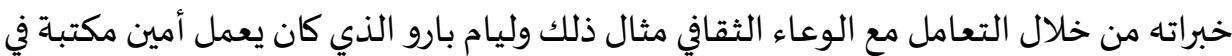

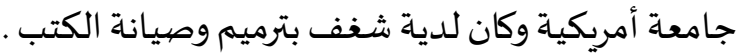
والمرمم من وجهة نظر الباحث هو الفرد الذي لدية مهارة يدوية وتلقي تثقيف أكاديمي في حفظ التراث الثقافي وخبرة عملية على استخدام أصابعه في حفظ الأوعية الثقافية أو التراثية. 10/1 التعاون بين أخصيائي الترميم وأمين المكتبة إن التعاون بين أخصائي الحفظ وأمناء المكتبات يعمل على وجود خطط فعالة ومنظومة مشتركة للتأهب عند حدوث كارثة كما يتم وضع الخطط والسياسات الضرورية والتخطيط 
لنقل المجموعات كما يتضمن إدارة المجموعات تحديد التالف منها أو التي تحتاج إلى صيانة أو (soete, jeorge, lbid). تجليد

ويبدأ التعاون بين أمين المكتبة وأخصائي الصيانة في المكتبة بالتنسيق بينهما بمعني أن

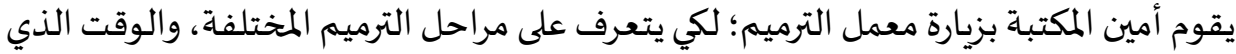

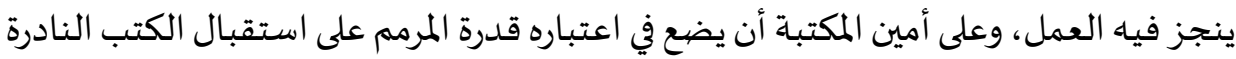

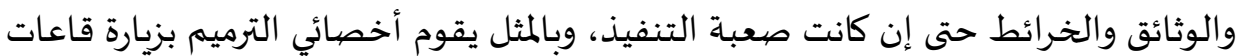

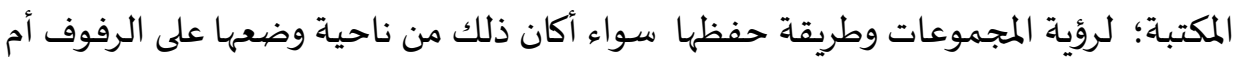

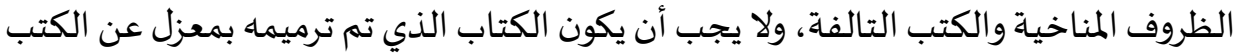

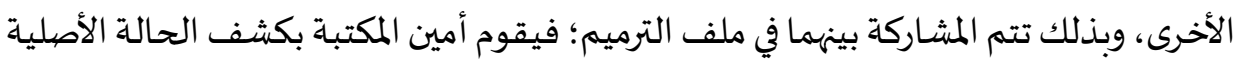

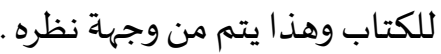
11/1 س سجل الترميم

من الضروري وجود استمارة أو سجل مع الوعاء أثناء إجراء الصيانة، ووجود قاعدة

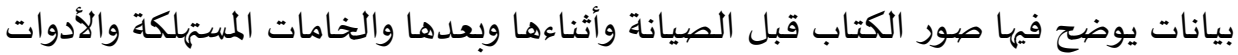
محسوبة كمًا وسعرًا وتعتبر هذ الاستمارة كاشفة لحالة الوعاء، ووثيقة أساسية لمعرفة الحالة الصحية للكتاب ويحتوي السجل على الآتي :

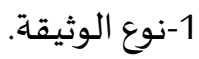
2- وصف العناصر التي تسمح بكشف الحالة الأصلية للكتاب. 3-وصف حالة الحفظ. 4- مشروع الصيانة. 5- الخامات والأدوات المستخدمة والتكلفة.

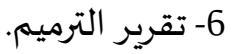


عند الانتهاء من أعمال ترميم الوعاء يقوم أمين المكتبة باستلام وفحص الوعاء جيدًا

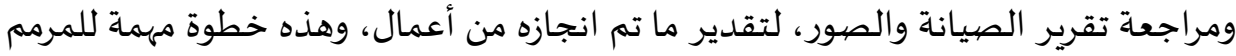
الذي يشهد ثمرة انجاز ما تم تحقيقه وللوقوف على حالة الكتاب، وبالتالي إعادة الوعاء إلى مكانه

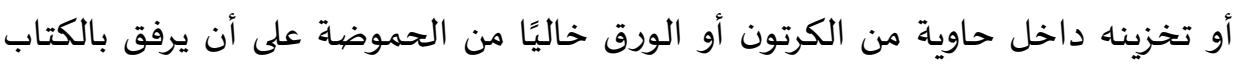

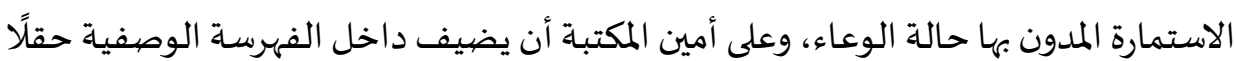

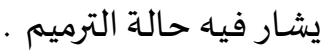

يجب على المرمم أن يعمل مع أمين المكتبة في أن يميزوا بين التدخل الضروري واللازم

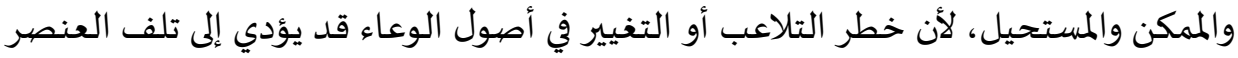

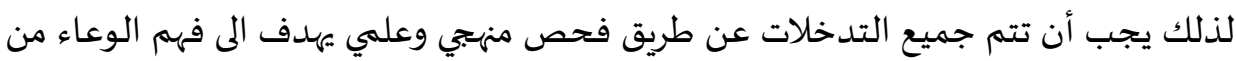
جميع جوانبه كما يجب مراعاة عواقب كل تلاعب في الأثر (oddos, lbid ).

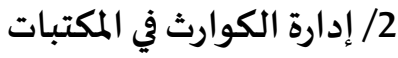

0/2 تمهيد

يقول جون ملتون "john Milton " إن قتل كتاب أشببه ما يكون بقتل إنسان بل إن

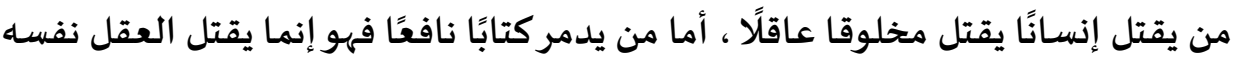

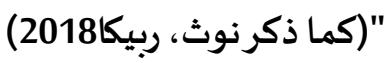

تعرضت بعض المكتبات لنكبات الحروب الأهلية، أو للحريق أو الهنب تحت الضغوط

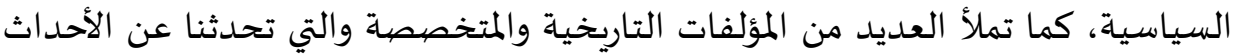

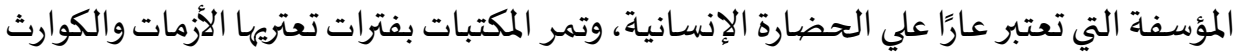

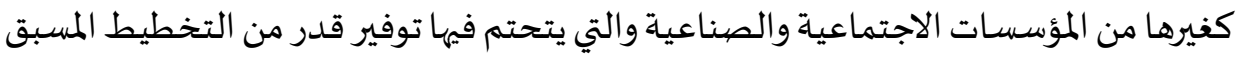

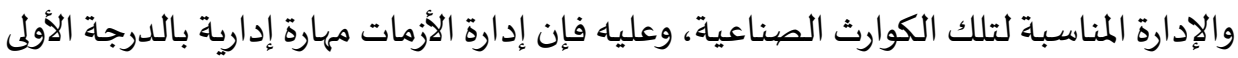

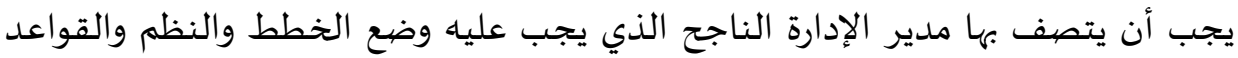
المناسبة، وتدريسها لكوادر أختصاصيي المكتبات، وتنظيم دورات تدريبية؛ لتقليل الخسائر وتجنب الأزمات ما أمكن .( صادق، أمنية 2002) 
وقد أتلفت الفيضانات التي اجتاحت فلورنسا عام 1966 قرابة مليوني كتاب، كان العديد منها مخطوطات نادرة وثمينة، وفي عام 1988م التهمت نيران مدمرة زهاء 3.6 مليون كتاب في مكتبة أكاديمية العلوم في ليننجراد، وعلى الرغم من أن مثل هذه الكوارث تصيبنا بالحزن، وتخلف في نفوسنا إحساسًا بالخسارة؛ فاستجابتنا لدمار الكتب من جراء الكوارث

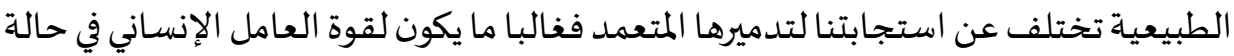

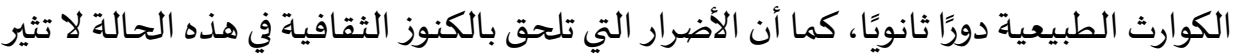

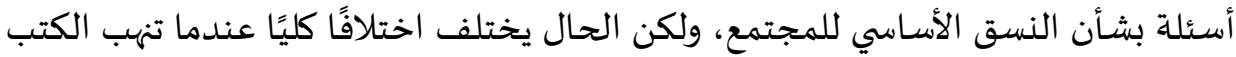
وتقصف المكتبات وتحرق بطريق منهجية؛ إذ تكون هنا بصدد هجمة متعمدة ومدروسة تستهدف ثقافة مجتمع ما ( نوث، ربيكا مرجع سابق). وتركز منظمة الإفلا لبرنامج الحفظ والصيانة PAC في الحفاظ على الأوعية الثقافية

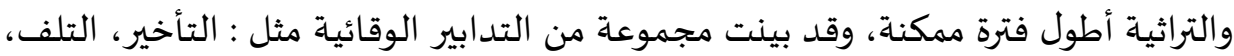

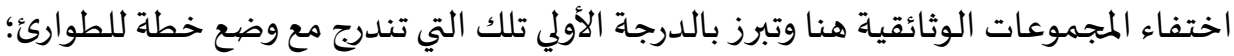
لذلك قررت منظمة الإفلا تنظيم عدد من الندوات والمؤتمرات العلمية وورش العمل التي تهدف

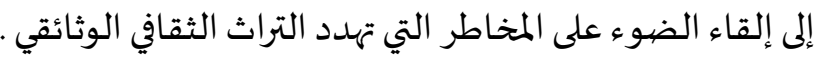
ففي عام 2003 أجريت دراسة استقصائية عالمية للمكتبات الوطنية وذلك لتحديد المكتبات التي لا يتوافر لديها خطة للطوارئ، وقد جاءت النتائج مثيرة للقلق فمن مجموع 177 مكتبة وطنية شملتها الدراسة وجد أن 39 مكتبة فقط لديها خطة للطوارئ، وأن 28 مكتبة لدية

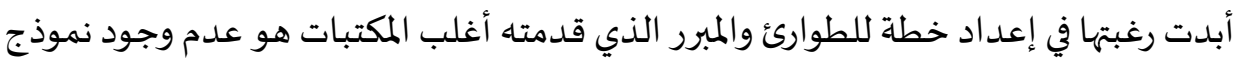

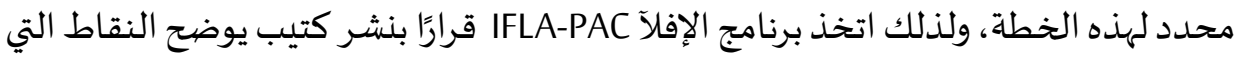
يجب اتخاذها بعين الاعتبار عندوضع خطة للطوارئ : مثل تقيم المخاطر ، إدارة المخاطر وكيفية التعامل معها عند حدوثها، إعادة التأهيل للوضع الطبيعي وتشكل هذه الموضوعات المكون

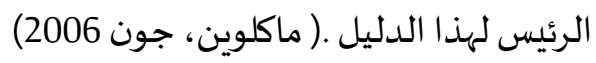

$$
\text { 1/2 تعريف الكوارث }
$$

تُعرِّف الأمم المتحدة الكارثة بأنها اضطراب خطير في أداء المجتمع، وتنطوي الكوارث على

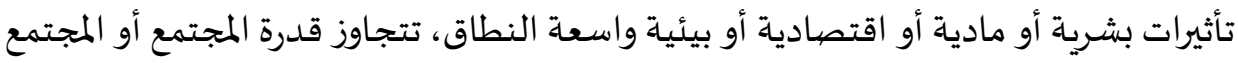


المتضرر في التعامل مع موارده الخاصة .كما تُعرِفِ جمعيتا الصليب الأحمر والهلال الأحمر إدارة

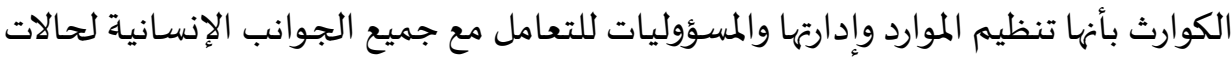
الطوارئ، ولا سيما التأهب والاستجابة والتعافي من أجل تقليل أثر الكوارث(F.C Cuny 1993). والباحث يري أن الكارثة هي تهديد أو صدمة تحدث بشكل مفاجئ سواء كان بفعل عوامل الطبيعة أو بفعل عوامل البشر؛ مما يسبب خسائر مادية وبشرية. 2/2 أنواع الكوارث

يوجد خمسة أنواع من الكوارث والتي تحدث بصورة طبيعية: -الكوارث الجيوفيزيائية: مثل الزلازل، والاهيارات الأرضية، وأمواج تسونامي، والنشاط البركاني - الكوارث الهيدرولوجية: مثل الانهيارات الثلجية والفيضانات. -الكوارث المناخية: مثل درجات الحرارة القصوى والجفاف وحرائق الغابات. -الكوارث الجوية: مثل الأعاصير، والعواصف أو اندفاعات الأمواج. -الكوارث البيولوجية: مثل الأمراض الوبائية، والأوبئة الحشرية أو الحيوانية يميز مكتب الأمم المتحدة للحد من مخاطر الكوارث الطبيعية فيما يتعلق بحجمها أو شدتها ، وسرعة ظهورها ، ومدتها ، ومجال انتشارها ، على سبيل المثال: الزلازل قصيرة المدة، وعادة ما تؤثر على منطقة صغيرة نسبيًا، بينما تتطور حالات الجفاف ببطء، وتتلاشى، O. ) Reilly, Naomi)

ويري الاتحاد الدولي لجمعيات الصليب الأحمر والهلال الأحمر أن الكوارث التي يصنعها الإنسان هي أحداث يتسبب فيها البشر، وتحدث في المجتمعات البشرية أو بالقرب منها غالبًا؛

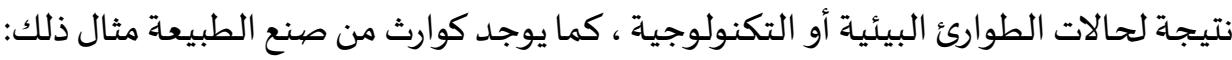

$$
\text { الحروب والحر ائق }
$$

لم تسلم دور المكتبات والوثائق ومراكز المعلومات من الحريق والتلف وأعمال النهب والسرقة والخراب والتدمير والتفجيرات التي حدثت عبر العصور، مثل مكتبة الإسكندرية 
القديماة، وحريق مكتبة الكونجرس، ومكتبة سراييفو، وغيرها والتظاهرات قد تكون سببًا من

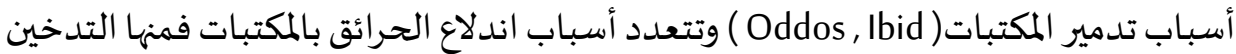

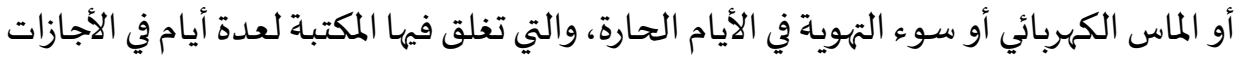

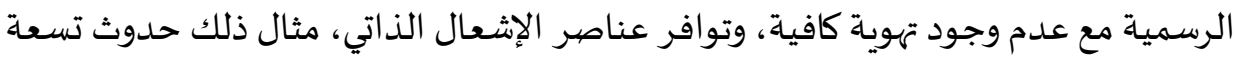

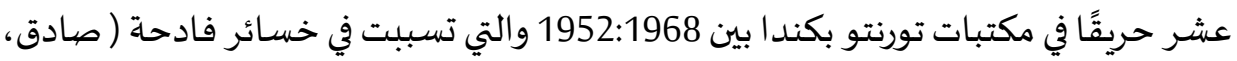

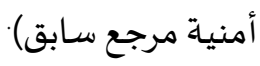

السرقة

هي ظاهرة قديمة؛ فقد كانت تعاني المكتبات في القدم من سرقة الكتب أو قطع بعض

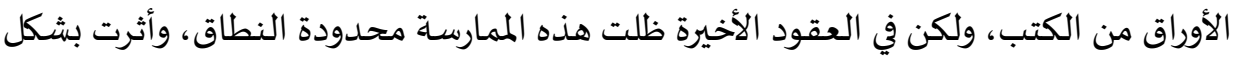

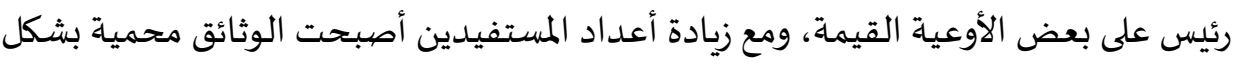

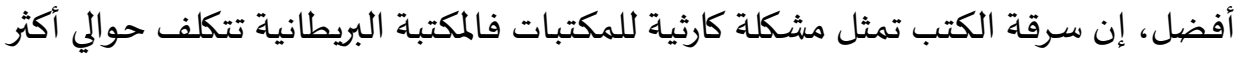

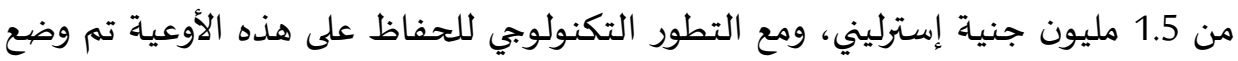

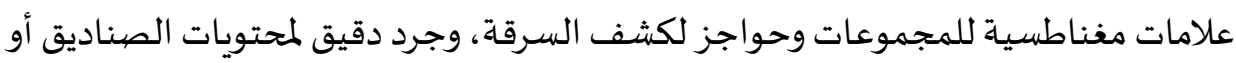

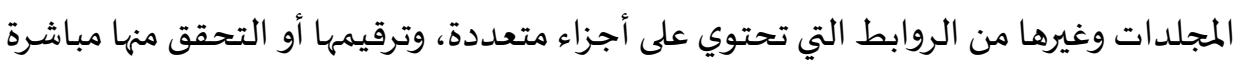

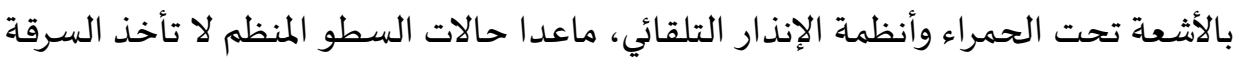

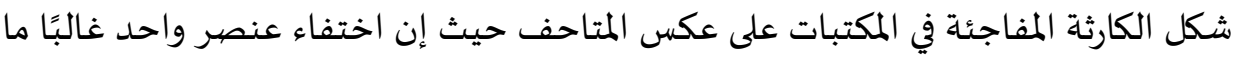

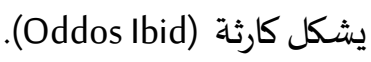

Libricide: إبادة الكتب

استخدم هذا المصطلح إلى التدمير واسع النطاق للكتب والمكتبات برعاية الأنظمة

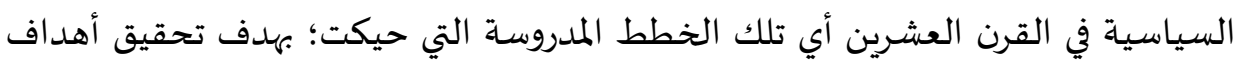

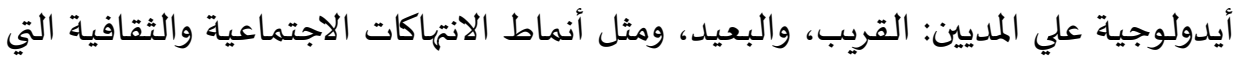

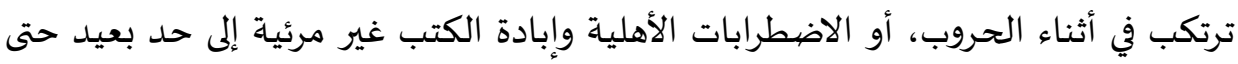

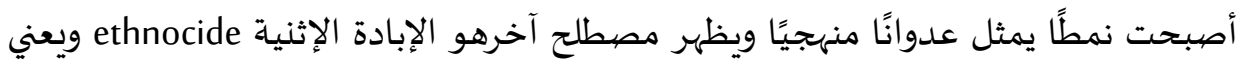


تدمير ثقافة ما، دون أن يعني هذا بالضرورة قتل حملتها ومصطلح الإبادة الجماعية ومان

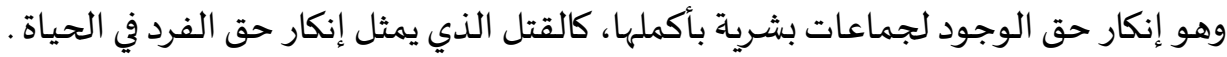
إن هذين المصطلحين صارا يستخدمان بطريقة فضفاضة، وغالبا ما توصف جرائم

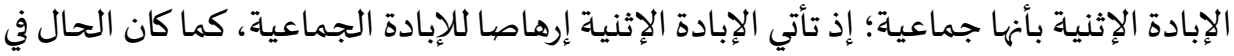

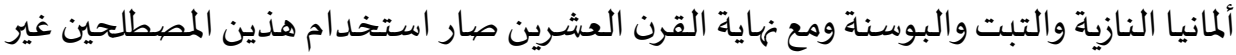

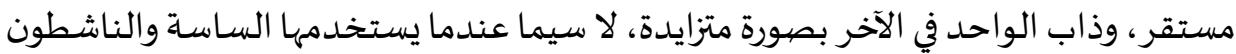

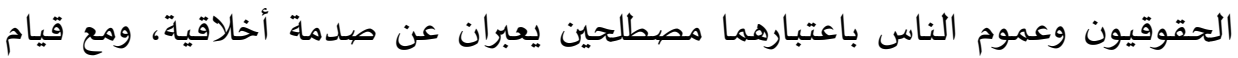
الإمبراطورات وانهيارها اتبعت الظروف المحيطة بتدمير المكتبات في العادة ثلاثة أنماط رئيسـاة: الأول ضياع المكتبات؛ نتيجة الاجتياح العام للمدن، والقصيور، والمعابد التي استولى عليها

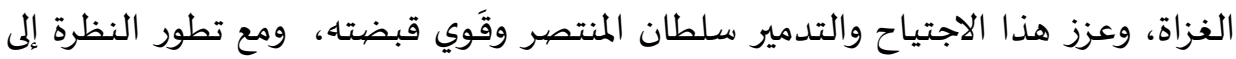

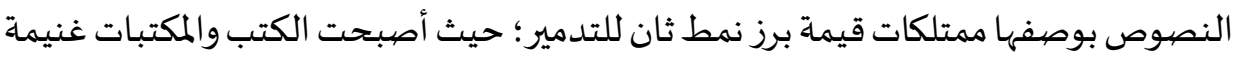

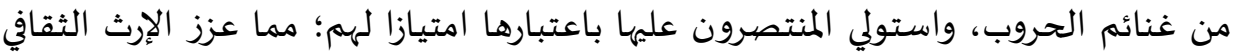

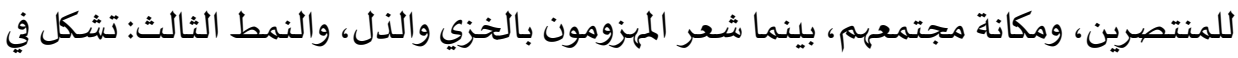
وجود الأنظمة الدينية والأيدولوجية التي صنفت مواد معينة باعتبارها ضارة، ودعت إنها إلى حظرها

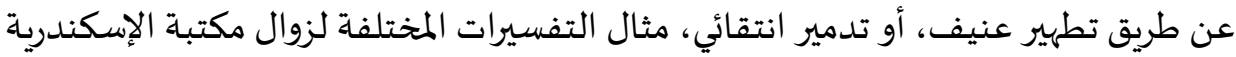

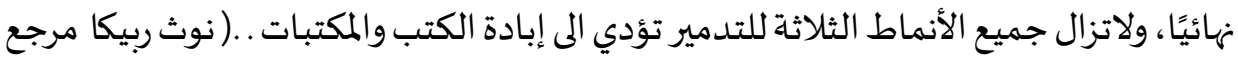

\section{الأمطاروالسيول والأعاصير}

تشكل المياه خطرًا كبيرًا على مقتنيات المكتبة، ويمكن أن تكون الأسباب داخلية ناتجة عن

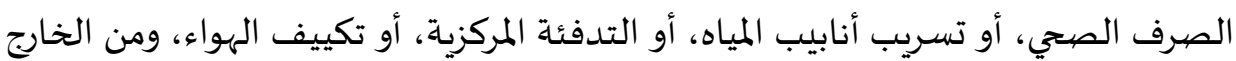

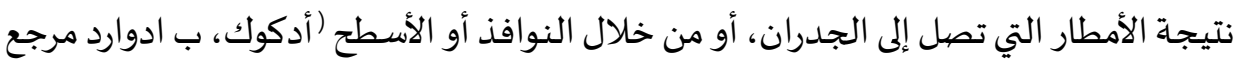
سابق)

وتتعرض بعض المكتبات لموجات من السيول والأعاصير والأمطار؛ حيث إن هذه المكتبات

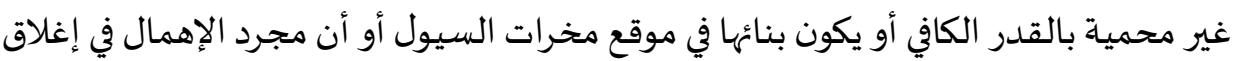
شباك زجاجي قد يعرض مجموعة مقتنيات قاعة بأكملها إلى التلف، أيضًا صينابير المياه 
ومصارف المجاري بالمكتبة تحدث أضرارًا جسيمة بالكتب، مثل غرق المجموعات وهذا النوع من

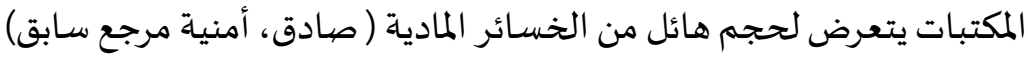
والورق يمتص الماء بنسب مختلفة تبعًا لعمر وحالة الورق؛ فالمخطوطات والكتب قبل

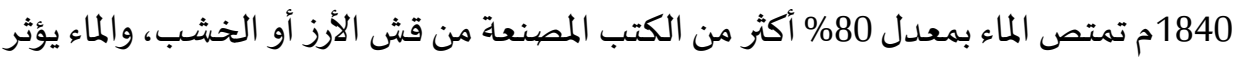

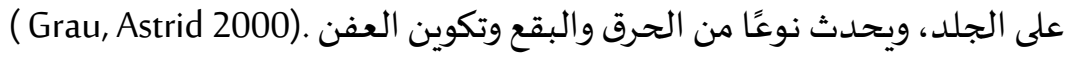
وعند حدوث تلف بالمواد المكتبية يجب على أمين المكتبة السرعة في إنقاذ المجموعات،

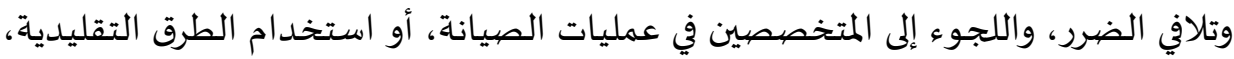

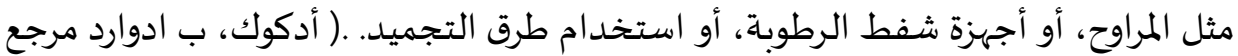
سابق)

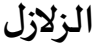

اهتزازات مفاجئة تصيب القشرة الأرضية ،وتحدث عدة أضرار، منها انهيار المبني أو ميله،

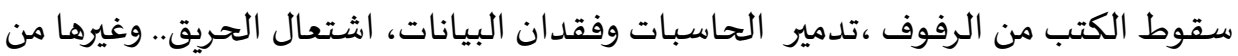

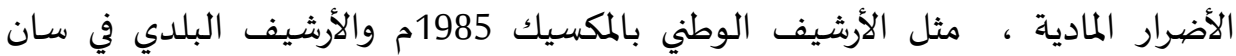

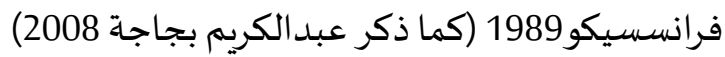

\section{الأوبئة والأمراض المعُدية}

يظن بعض الناس أن زمن الأوبئة قد انتهي؛ نتيجة التقدم العلمي والطبي، وأن البشرية

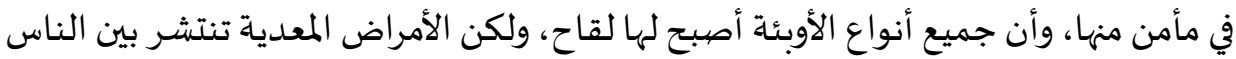

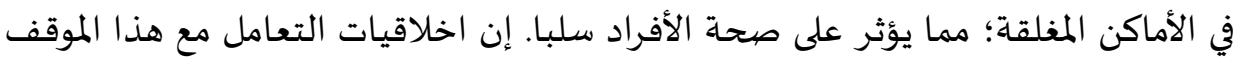

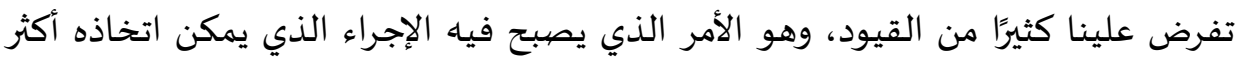

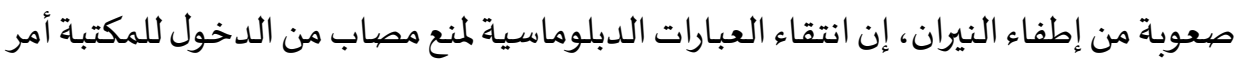

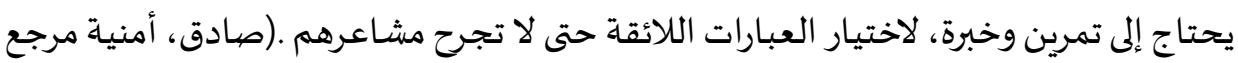


مثال ذلك ظهور فيروس كورونا (covid 19) والذي أحدث ارتباك في جميع أنحاء العالم 2020وهو مرض يصيب الجهاز التنفسي، وقد أصاب الملايين وفتك بالآلاف، وقد انتشر هذا الوباء من خلال رذاذ اللعاب أو إفرازات الأنف عندما يسعل الإنسان؛ ونتيجة قوة هذا الوباء

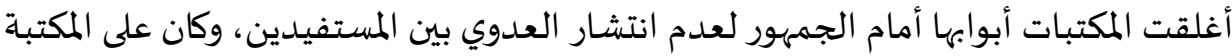

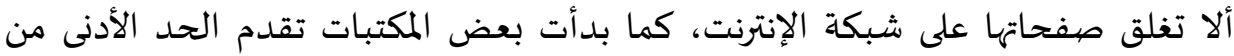

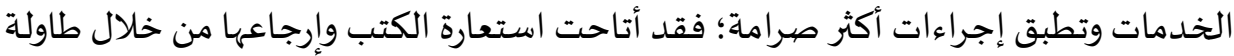

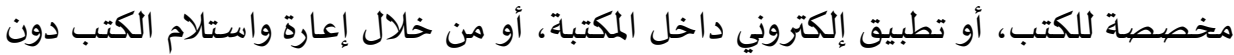

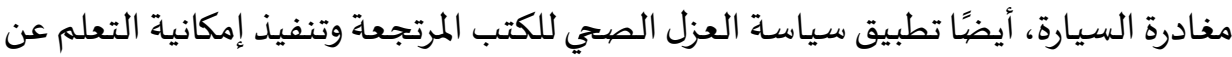

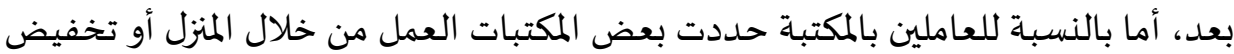

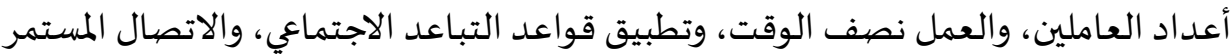

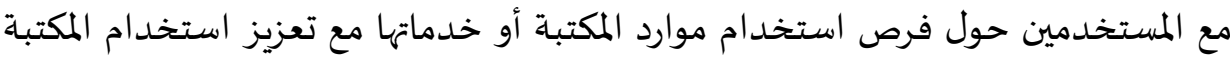

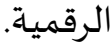

قدمت بعض المكتبات العببية محاضرات على الشبكة الدولية للمعلومات مثل المكتبة الوطنية الفرنسية معارض افتراضياة، وتقوم المكتبة الوطنية الأسبانية بالترويج لمحتواها الرقي

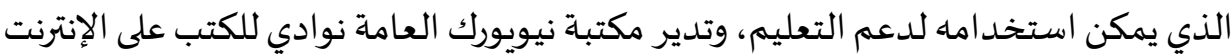
باستخدام تطبيق simply E والذي يعتمد على تحميل تطبيق برنامج يقوم بإعارة الكتب إلكترونيًا، كما قامت مكتبة الإسكندرية بعرض مجموعاة من الفيديوهات التي يتبادل فيها أختصاصيو المعلومات خبراتهم، أيضيا قامت مكتبة قطر الوطنية بتقديم بعض المحاضرات

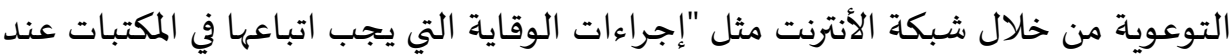

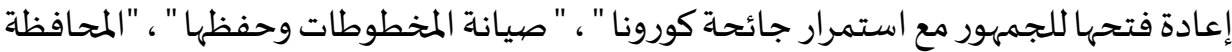

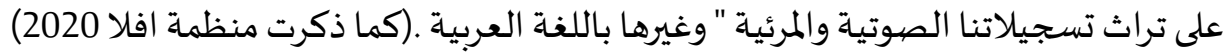

\section{3/2/الوقاية من الكوارث المحتملة}

يقصد بالوقاية تحديد الإجراءات اللازمة؛ لتجنب وقوع الكارثة و حماية المجموعات من الضرر، والوقاية هى مجموعة من التدابير، الهدف منها منع وقوع حوادث أو كوارث محتملة، 
أما الحماية فتشمل كل الإجراءات التي تحد من هذه الأضرار، والتي قد تتأثر بها المقتنيات الثقافية.(ماكلوين جـون، مرجع سـابق)

وبالنسبة للزلازل لابد من تحديد قوة الزلزال الاحتمالية بمقياس ريختر ، وذلك عن طريق الاتصال بإدارة الأرصاد الجـوية، أو مراكز البحث المختصية بالزلازل، وجمع معلومات عن الزلازل السابقة، وتقييم قدرة المبني على مقاومة الزلازل المحتملة بمساعدة المهندسين المختصين. أما عن الفيضانات، فينبغي جمع معلومات عن الفيضانات السابقة، ومراجعة حواجز الأمواج والتأكد من ارتفاع السـدود، ووضع الكتب بمخازن علوية، (شـاهد الباحث خلال زيارته للمكتبة الوطنية الفرنسية مخازن مرتفعة جدًا عن سطح الأرض؛ وهي عبارة عن حاويات بها كتب محفوظة داخل صيناديق تعمل آليًا) مع الاتصال الدائم مع الجهة المنوط بها التنبؤ بحدوث الفيضيان والأمواج الكبرى أو التسونامي.

وبالنسبة للمبنى قد تكون الكارثة نتيجة أخطاء هندسية، مثل شبكات الصرف الصبي أو مواسير المياه؛ لذلك يجب أن يخضع المبنى للصيانة المستمرة، ومنع مرور أنابيب المياه داخل المخازن، مراقبة الأنابيب باستمرار. وأما عن المستفيدين، فينبغي مراقبة المبنى عند الدخول والخروج، ومراقبة الوافدين على المبنى أثناء ساعات العمل، وتفتيش حقائب الزوار والباحثين، ووضع نظام آلي للحريق مرتبط بجهاز الرقابة المركزية ويعمل آليًا عند وجود دخان أو مواد تحترق، ووضع نظام يدوي على سبيل الاحتياط.( بـجاجة مرجع سابق)

وهناك عدة مكتبات تتبع سياسـة مقاومة الكوارث، مثل المكتبة الوطنية الطبية بأمريكا Institute للديها مركز أبحاث إدارة معلومات الكوارث National Library of Medicine: Disaster Information Management Research Center من 2006 وحتى 2016 ؛للتأهب عند حدوث كوارث، وتهتم بجمع معلومات صحيحة متعلقة بالكوارث ثم تنظيمها ونشرها عن طريق محاضرات وندوات لأمناء المكتبات من وقت لآخر، مع (Rattan,P. توفير معلومات في قواعد البيانات ذات الصلة وكيفية التصرف عند حدوث أزمات 
4/2 دور الإنسان في تلف المخطوطات والكتب

يُعد الإنسـان هو المسئول الأول عن تلف هذه الأوعية الثقافية في وجود هذه العوامل السـابقة البيولوجياة والكيميائية وأخيرًا الفيزيقية؛ فالإنسان يستطيع أن يمنع أو يحد من تأثير هذه العوامل، ويستطيع أن يسمح لها بالتغلغل داخل هذه الأوعية، فترك المخازن بدون مكيفات

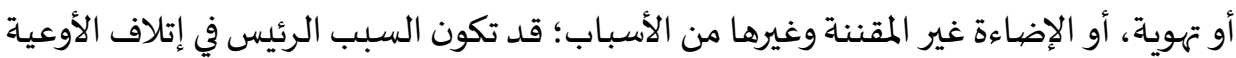

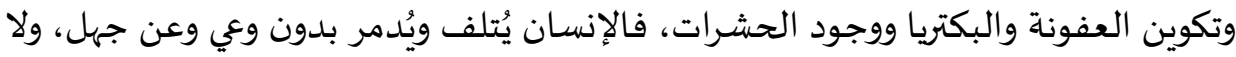

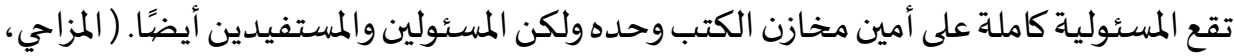

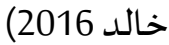

العوامل البشرية التي تؤدي إلى تلف الأوعية الثقافية

التقليب المستمر والسريع للصفحات يؤدي إلى تمزق وتشوه حواف الصفحات. التقليب بأصابع ملوثة بالحبر أو الماء أو التراب يسبب بقعًا وبصهمات على الورق. ثني الورق وتركه فترات طويلة يؤدي إلى تكسير الألياف. الأكل والشرب والتدخين داخل المخازن. الضغط على كعب الكتاب عند تصويره.

عدم وضيع الكتاب بشكل منتظم على الرفوف، فالوضيع المائل للكتب يؤدي إلى ألتواءها. عدم وجود معايير لدرجات الحرارة والرطوبة والضوء. الإهمال في حمل الكتاب أو سحبه من مكانه، مما يؤدي إلى تلف الكعب من أعلي. الكتابة على الورق، وظهور علامات داخل الكتاب بأقلام ملونة. قسم التجليد بالمكتبة غير مؤهل على الإطلاق. عدم وجود خطة للتعقيم الدوري. سرقة بعض الصفحات من الكتب.( فرحات ، أحمد 2010). 
3/ الطرق الكيميائية والفيزيائية في التعقيم

1/3/3 الطرق الكيميائية

\section{Alcohols 1/1/3 الكحول}

الكحول والفينول مركبات عضيوية، تحتوي جزيئاتها على مجموعة أو أكثر من مجموعات

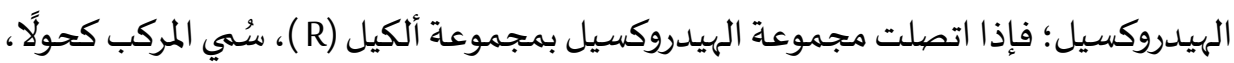

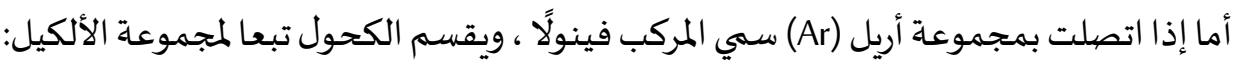
إلى الكحول الميثيلي CH 3 ، والكحول الإيثيلي CH وترى"Bacilkova") (as cited s.sequeira2012) أن الكحولات هي مبيدات ميكروية نشطة

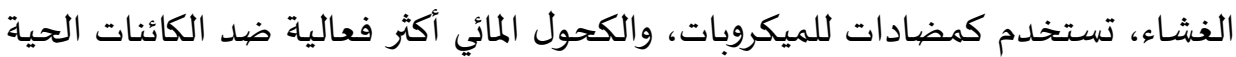
الدقيقة، من الكحول النقي بتركيزات بين 50 ٪ و 90 ٪، وذلك اعتمادًا على نوع الكحول. يمكن أن تكون الكحولات فعالة ضد الأشكال النباتية للبكتيريا، والفطريات،

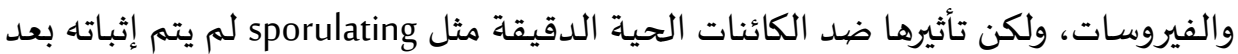
فهو مستخدم للتطهير من الجراثيم وليس التعقيم .

\section{C2 $\mathrm{H}_{5} \mathrm{OH}$ Ethanol الإيثانول أو الكحول الأيثيلي 1/1/1/3}

يُعد من الكحولات الأولية أحادية الهيدروكسيل، وهو من أقدم المركبات العضيوية التي حضرت صناعيًا فقد حضره قدماء المصريين منذ أكثر من ثلاثة آلف عام من تخمر المواد

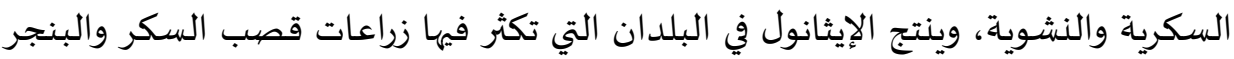

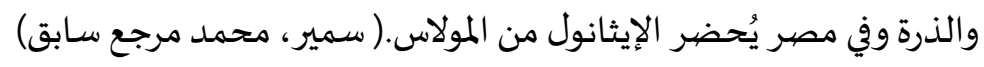

والإيثانول (Bacilkova" أن أولى الدراسات المتعلقة بتأثيرات الإيثانول على البكتيريا تعود إلى عام الإيلى (s.sequeira Ibid )

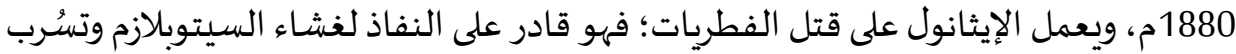
العصارة الخلوية؛ مما يؤدي في النهاية إلى تفكك الخلية. 


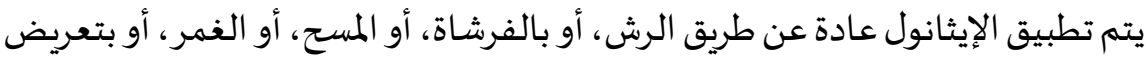

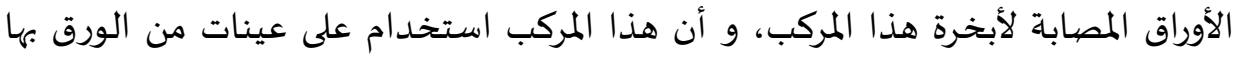

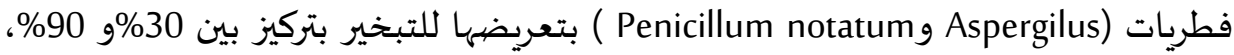
يمكن أن تمنع إعادة نمو الفطريات لمدة 14 يوم من إجراء عملية التبخير، وبالنسبة للمواد السميكة مثل الكتب، فالعلاج ليس فعالًا.

ومن عيوب الكحول أنها يسبب تغيرات على الورق الشفاف عند غمره تشمل فقدان لمعان

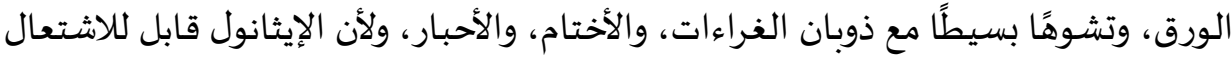

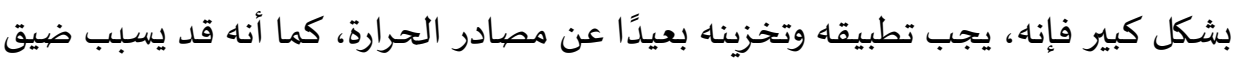

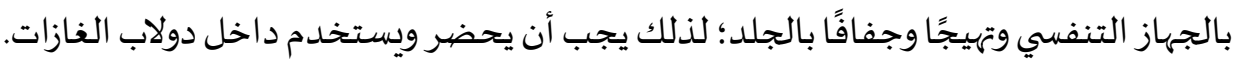

Alkylating Agents 2/1/3 عوامل الألكلة

هي نوع من الأدوية المستخدمة في علاج السرطان، الذي يتداخل مع الحمض النووي للخلية ويمنع نمو الخلايا السرطانية. يمكن أن تتحد عوامل الألكلة مع المجموعات الأمينية والكربوكسيلية والسلفهيدريل والأمينية في البروتينات والإنزيمات في الخلية الميكروبية، هذه المركبات قادرة على إبطال نشاط المداط البكتيريا والفطريات والفيروسات حسب " (s.sequeira lbid ) Russell

\section{C $\mathrm{C}_{2} \mathrm{H}_{4} \mathrm{O}$ أكسيد الإيثيلين}

هو غاز عديم اللون، وقابل للاشتعال عند درجة حرارة الغرفة والضغط وأكسيد

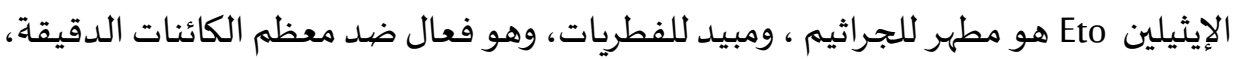

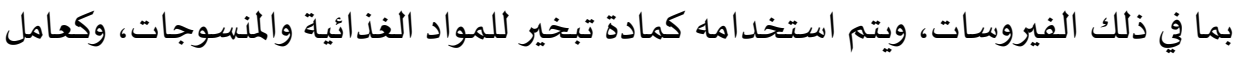
للتعقيم الغازي للمستحضرات الصيدلانية . استخدم هذا المبيد بكفاءة وفاعلية في تعقيم المكتبات والمتاحف والوثائق؛ لقوة

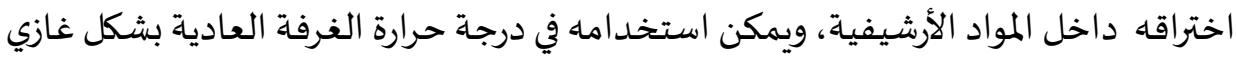

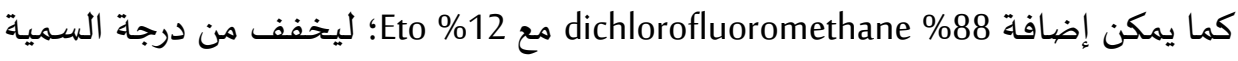
والاشتعال والانفجار والوقت المحدد لتعقيم الكتب يتراوح من ثلاث ساعات الى 24 ساعة؛؛ إلا دئ ديه 
أن"s.sequeira Ibid ( "Strassberg ينصح بزيادة مضاعفة الوقت عند تعرض هذا الغاز لتعقيم الحشرات ومقاومة العفن .

وينصح"(s.sequeira lbid) "Mendos) أن يتم تهوية المكان بعد إجراء التعقيم جيدًا؛

حتى لايتعرض الفرد إلى أمراض سرطانية، كما يؤثر Eto على الخواص الكيميائية، والفيزيائية

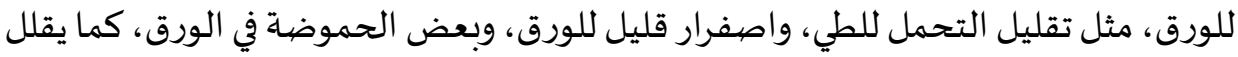

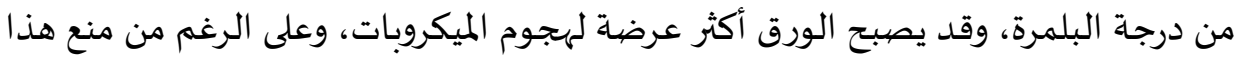

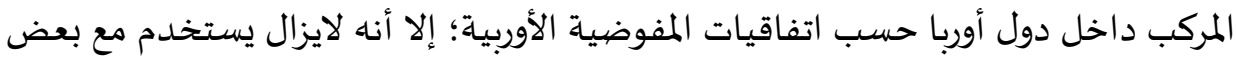

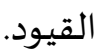

شاهد الباحث تعقيم الكتب باستخدام أكسيد الاثيلين في مدينة سابليه، وهي من المدن الصغيرة تقع غرب فرنسا، وبها مكان مخصص للتعقيم فوق سطح المكتبة الوطنية الفرنسية وذلك عامى 1994/1993 من القرن الماضي .

\section{Formaldehyde 2/2/1/3 الفورمالدهيد}

الفورمالدهيد مركب عضوي من أبسط الألدهيدات الأليفاتية ويعتبر من الغازات

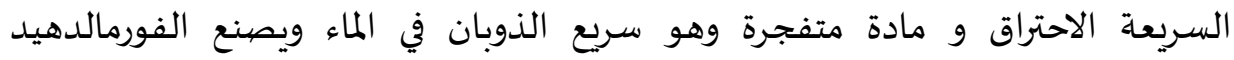
methanol وله رائحة كريهة و نفاذة وعديم اللون (B. agarwal 2011).

باعتباره مادة تبخير يتم وضع هذا الغاز داخل فرن مغلق عند درجة حرارة 30 درجة

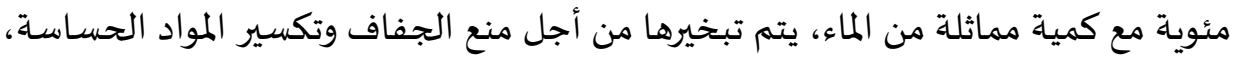

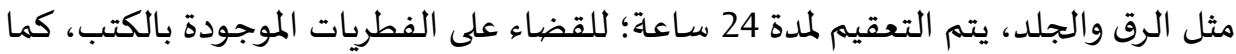

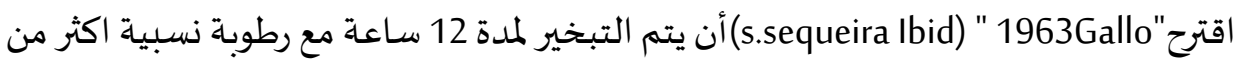
60\% ،ودرجة حرارة أكثر من 18 درجاة، ثم يتم تعريض الكتب في الهواء لساعات طويلة أو لأيام حتى تتم إزالته من أسطح الكتب او المواد ـ مرداه أما"S.sequeira Ibid) 1999"Valentin \& Garcia) فيري كل منهما أن هذا الغاز له تأثير محدود على الفطريات. 
ومن عيوبه أن له تأثيرًا ضارًا على الكتب والوثائق المتمثلة في ضعف، ومرونة الورق، وحموضية والمواد المحتوية على البروتين، مثل الرق والحرير والجلد، كما يعمل على صدأ أنسأ وتأكل

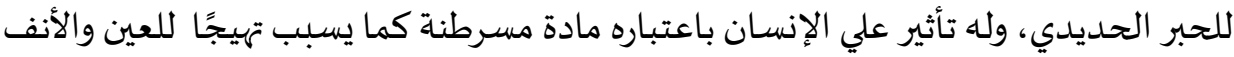

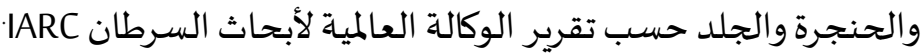

Azole 3/1/3 الأزول

يعد من المركبات المضادة للفطريات، والتي تنقسم إلى imidazoles و triazoles ، وفقا

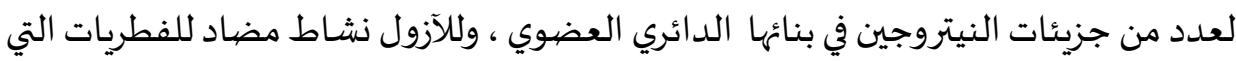
تصيب الجلد والأغشية المخاطية.(Britannica) يحتوي الأزول على ذرتين أو ثلاث من ذرات فرات

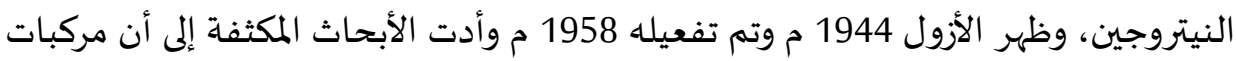

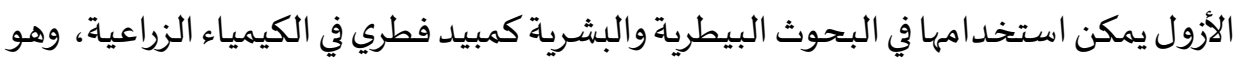
يعمل على وقف نمو الفطريات.

وقد اختبر"Fabri" (s.seqeira.lbid) وآخرون تأثير الأزول كمضاد للجراثيم والفطريات

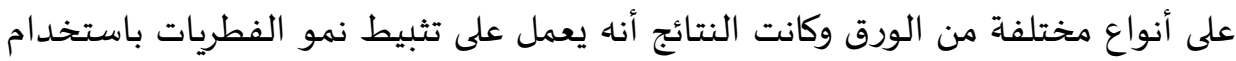

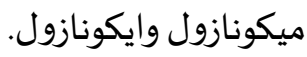

\section{Essential Oils الزيوت الأساسية 4/1/3}

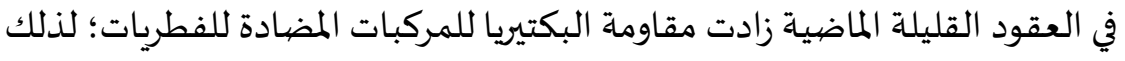

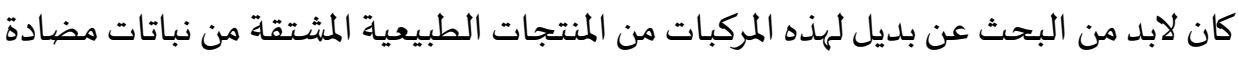

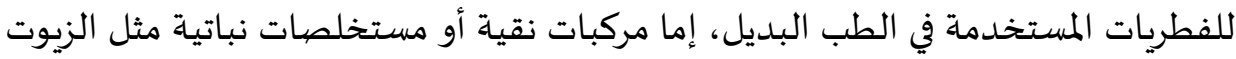

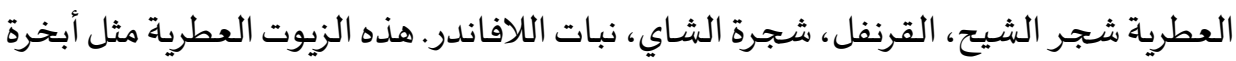
Linalool LN

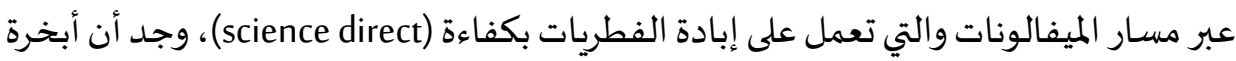

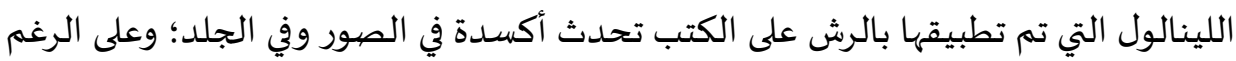

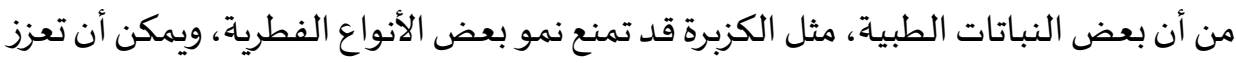

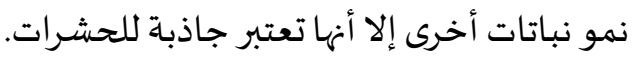


Phenol derivatives 5/1/3 مشتقات الفينول

يوجد العديد من مشتقات الفينول المستخدمة في خصائصها المطهرة والحافظة، هذه

المركبات هي مضادات للفطريات النشطة؛ كما تعمل مشتقات الفينول، على تفكيك أيونات الهيدروجين، وقادرة على تشكيل الأملاح، مثل:

\section{Dichlorophen 1/5/1/3 ثنائي كلوروفين}

يعرف تجاريًا باسم GD Panacide or Preventol تم إعداده 1929م، استخدم كمبيد

للفطريات الموجودة بالورق والكرتون والمنسوجات والمواد اللاصقة، يستخدم لعلاج الالتهابات الفطرية الموجودة بالجلود، ليس له تأثير قوي على الفطريات، ويري S.sequeira Kowalik (أن هid ) والأحبار والورق؛ نتيجة وجود الكلورالذي يسبب تهيج للعين والجلد.

Thymol 2/5/1/3 الثيمول

مادة فينولية لها تأثير قوى جدًا كقاتل لجميع أنواع البكتريا والفيروسات، وهو مركب

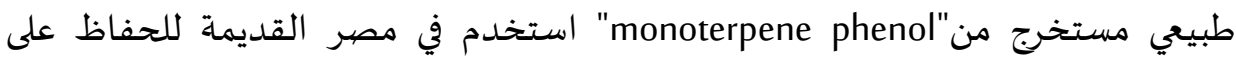

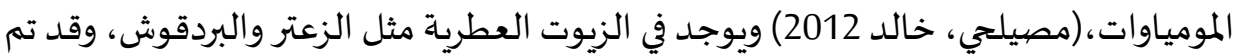
استخدامه كمبيد حشري؛ فهو قادر على النفاذ داخل الخلية الجرثومية، واستخدم بكفاءة

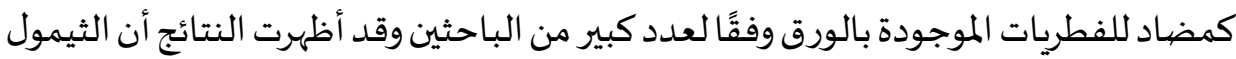

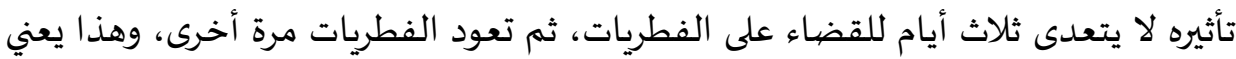
ضعف تأثيره كمضاد للفطريات، والثيمول قد يهاجم الغراء، ويذيب الأحبار ويترك بعض التهات الآثار على الرق والورق، وقد يغير من لون الورق.

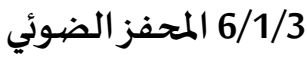

مادة تمتص الضوء وتسهل التفاعل عند إضافتها، وتظل دون تغيير في نهاية التفاعل

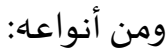


Titanium $\mathrm{TiO}_{2}:$ 1/6/1/3 التيتانيوم

وهو عنصر شديد الصلابة، ولكنها أقل كثافة، وتستخدم سبائكاه مع الألومنيوم في صناعة الطائرات والمركبات الفضائية؛ لأنه يحافظ على متانته في درجات الحرارة المرتفعة في الوقت الذي تنخفض فياه متانة الألومنيوم، كما يستخدم في عمليات زراعة الأسنان والمفاصل

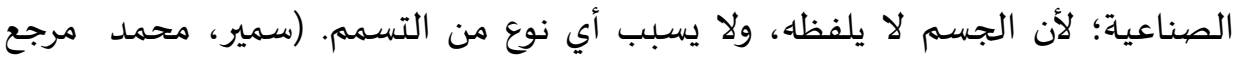
سابق)وقد استخدم والأعمال الفنية من تأثير الأشعة فوق البنفسجية والبكتريا والعفن والغازات الملوثة،تم خلط

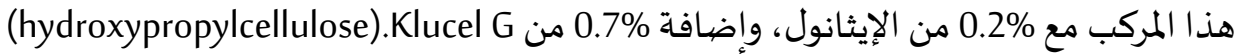
عن طريق الرش لعينات من الورق، بهاه نوعان من الفطريات:

"niger and Penicillium" هذا المركب يمنع تشكيل الأغشية الحيوية ولا يقتل الكائنات الحية الدقيقة، وقد رأت الوكالة

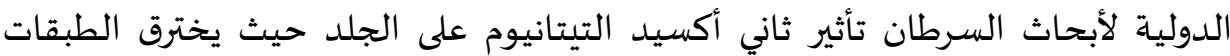

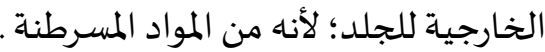

Quaternary ammonium compounds (Quats) 7/1/3 مركبات الأمونيوم الرباعية تم اكتشاف مركبات الأمونيوم الرباعية بواسطة"1851 August Hofmann" (s.sequeria Ibid)

\section{Dimethyl-lauryl-benzyl: ammonium bromide 1/7/1/3}

بروميد الميثيل هو مبيد آفات مقيَّد الاستخدام (RUP) ؛بسبب السمية الحادة المرتفعة بالنسبة له، يعرف تجاريًا باسم Sterinol يستخدم في الطب كمطهر منخفض المستوى، وهو مبيد غير نشط . تم اختبار هذا المركب من قبل "s.sequeria Ibid)"Rozanski) في تجربة على

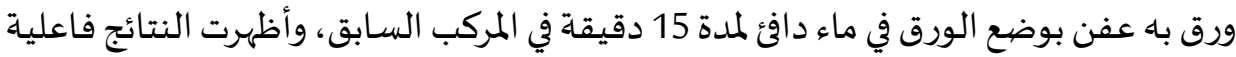

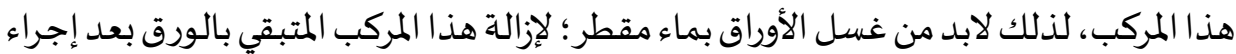
المعالجة؛ حتى لا يؤثر بشكل سلبي على الخصائص الفيزيائية للورق، مثل درجة الحموضية وبياض الورق ومحتوي الألفا سليلوز. 


\section{Lauryl-dimethyl-carbethoxymethyl ammonium bromide 2/7/1/3}

الاسم التجاري Cequartyl BE يستخدم في المكتبات، ودور الوثائق للقضاء على العفن

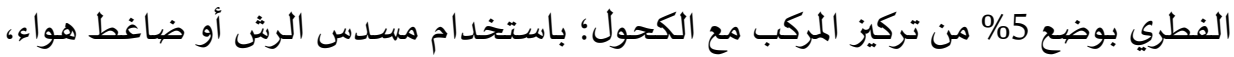
وتكون نسباء 5\% من المركب في 1 متر مكعب، وقد اقترح "S.sequeria Ibid )"Triolo ) غمر الورق داخل هذا المركب، وبتقادم المحلول على الورق، تم وضع الورق في درجة حرارة 105 درجة مئوية

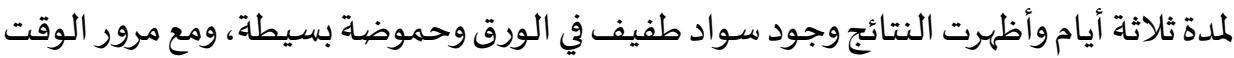

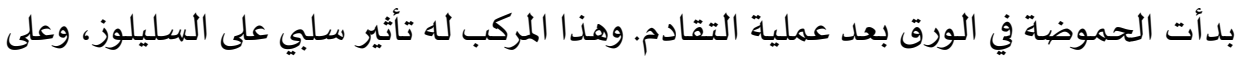
الغراءات، والأحبار، ويفضل استخدام واق للأنف عند اجراء التعقيم؛ لأنه يعمل على تهييج

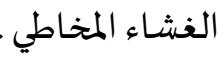

2/3 الطرق الفيزيائية

Dehydration 1/2/3 التجفيف

الرطوبة من العوامل الرئيسة التي تساعد على نمو الفطريات، ويعتبر الجفاف من أفضل الطرق لوقف نمو الفطريات على المواد المبللة، فهي تنفذ سريعا لمنع تطور الميكروبات وينصح

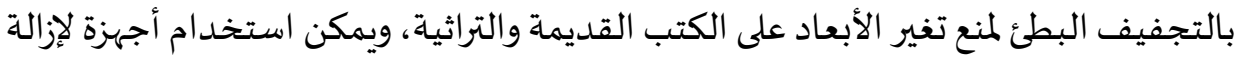

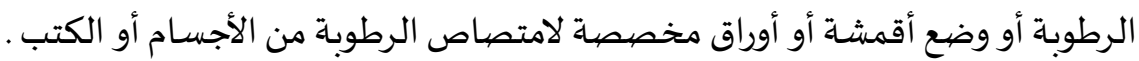

\section{Gamma $\boldsymbol{\gamma}$ - Irradiation 2/2/3 أشعة جاما}

اكتشفت أشعة جاما بواسطة العالم الفرنسي "Villard"في العام 1900م، وأشعاة جاما هي عبارة عن إشعاع كهرومغناطيسي؛ يستخدم في العديد من المجالات الطبية والدوائية والزراعية للتعقيم، ويتم الحصول على هذه الأشعة من معدن الكوبالت 60 ،وهي قادرة على اختراق روابط لمهري الكربون، وتدمير الحمض النووي الخلوي DNA.

استخدمت هذه الأشعاة في روسيا عام 1960م؛ لتعقيم المواد الورقية باستخدام جرعات

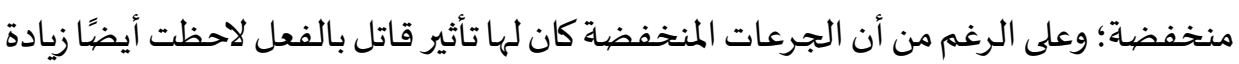

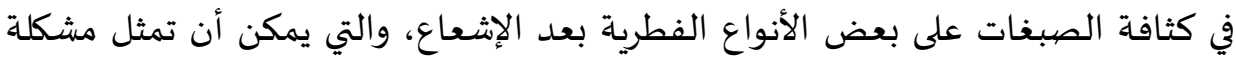

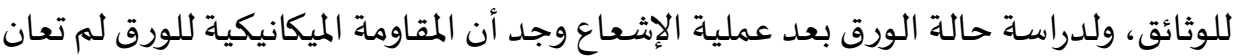


من أي تعديل، وبعد عملية التقادم الأصطناعي وجد أن الورق يعاني من بعض التغيرات؛ وهي

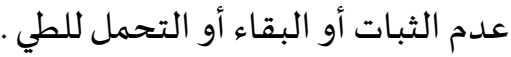

3/2/3 التيارات العالية التردد:High Frequency Current

وهو تيار كهربائي متناوب له تردد 10.000 دورة أو أكثر في الثانية(free dictionary 2018) استخدمت هذه الطريقة في روسيا 1947م ؛ لتجفيف الوثائق الرطبة ولاحظوا أن هذه الطريقة قادرة على قتل الفطريات ـ تتميز هذه الطريقة بسرعتها الفائقة؛ حيث يتم وضع الوثائق

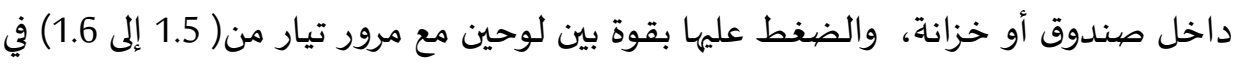

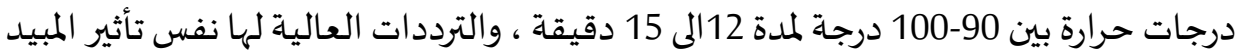
الحشري؛ مع أهها لا تحتوي على أي كيماويات، ولكن هذه الطريقة تركت آثارًا سلبية بسيطة

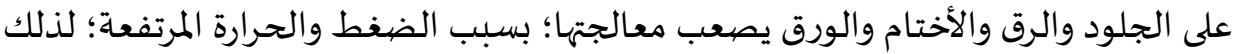

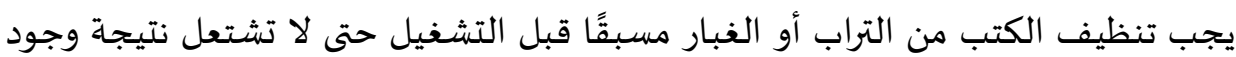

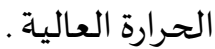

\section{Law- Oxygen Environments 4/2/3 أجواء الأكسجين المنخفض}

تعني استخدام الأكسجين المنخفض، و الكربون وثاني أكسيد النيتروجين، وهو أمر شائع

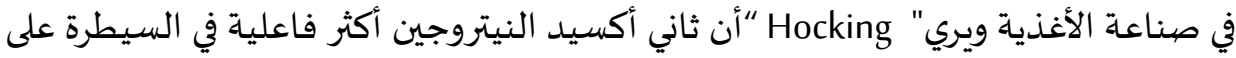

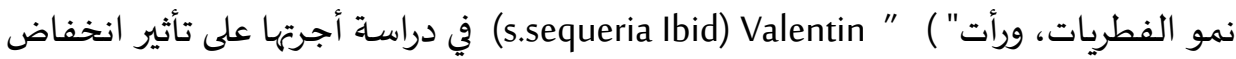

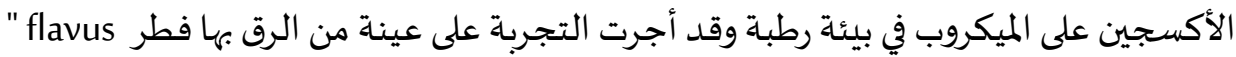

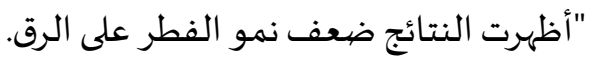

إن الفكرة تعتمد على خفض الأكسجين واستبد اله بالنيتروجين؛ لأن الفطريات تحتاج

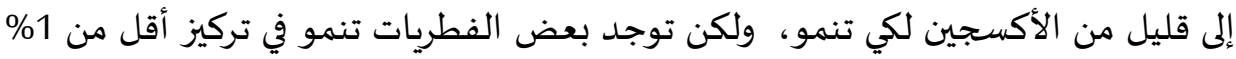

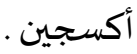


الطرق الكيميائية والفيزيائية المستخدمة في مكتبة الإسكندرية لمقاومة آفات مصادر المعلومات المطرف المات

استخدمت مكتبة الإسكندرية وهيئة الآثار المصرية والجامعة الألمانية في مصر ومراكز

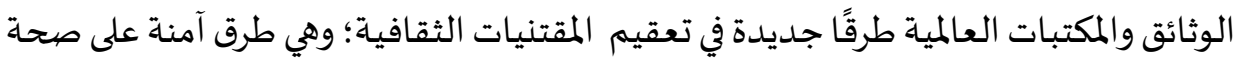

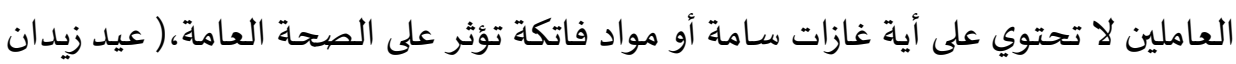
2016) مثل:

very low جهاز معالجة الحشرات بأكسجين منخفض بدون كيماويات او سموم oxygen(veloxy)

إن أول اشارة إلى إمكانية استخدام المناخ المتحكم فياه في مكافحة الآفات بالمتاحف، كان

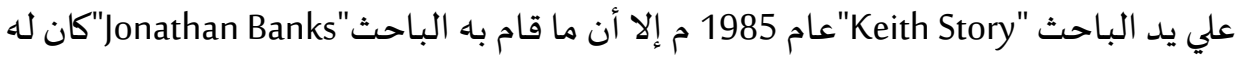

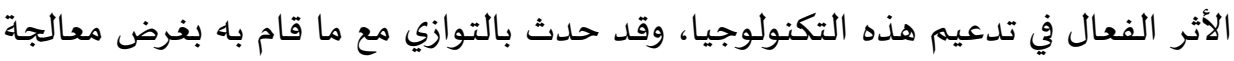
المومياوات الملكية لهيئة الآثار المصرية.

وهو عبارة عن استخدام الغازات الخاملة، مثل الأرجون والنيتروجين، أو استخدام ثاني

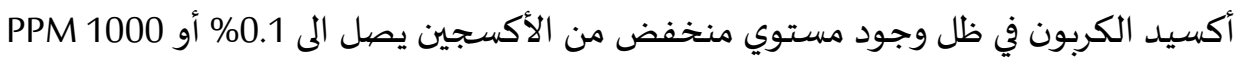

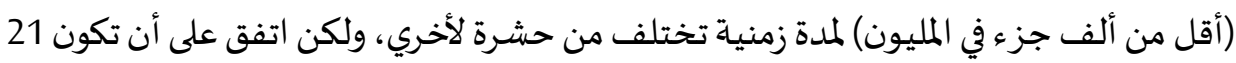

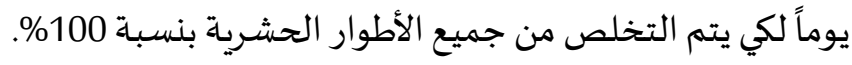

مز ايا نظام الأنوكسيا

1- كفاءة عالية تصل إلى ( 100\% ) ؛ نتيجة قدرته علي التخلص من جميع الأطوار

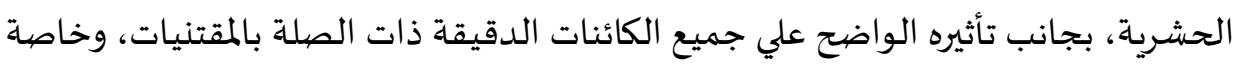
الفطريات.

2- يعتمد علي مكونات صديقة للبيئة نظرًا لاعتماده علي خفض نسبة الأكسجين وإحلال النيتروجين بدلا منه، والذي يشكل ما يقرب من ( 78\%) من الهواء الجوي؛ لذا فهو قليل النفقات مقارنة بالطرق التقليدية. 
3- ليست له أي تأثيرات سلبية علي الأحبار والصبغات، وجميع المواد المصنوع منها تلك المقتنيات؛ لذا يستخدم فيما يعرف بالحفظ الوقائي 4.Preventive conservation- سهولة التعامل مع هذا الجهاز وأمانه، حيث إنه لا يشكل أي خطورة تذكر علي الإنسـان؛ نظرًا لاعتماده

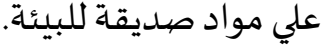
5- يعد هذا الجهاز دعما للنظام المتبع للمكافحة بمكتبة الإسكندرية والقائم علي برنامج المكافحة المتكاملة للآفات. (IPM) والموصي به من جهات عديدة، مثل IFLA . 6- لا يعتمد هذا النظام في فكرة عمله علي استخدام أية مواد سـامة (كما هو متبع في الطرق التقليدية لمعالجة المقتنيات)؛ حيث إن لها أثار سلبية متعددة، تتمثل في الآتي: O تشكل خطورة بالغة علي صحة الإنسان لكونها في الأسـاس مادة سامة. O ذات كفاءة محدودة علي الكائنات الدقيقة، ولا تحدث التأثير المطلوب في كل الأطوار الحشرية. O تحدث تأثيرات سلبية علي الصبغات والمواد التي تتكون منها تلك المقتنيات. O ت تعتبر من الملوثات المعروفة للنظام البيئي. O ذات تكلفة مرتفعة، كما أنها تحتاج لأماكن ذات مواصفات خاصة. تم التوصية باستخدام نظام الأنوكسيامن خلال عدة مشروعات بحثية أوربية: - - المشروع الأوروبي لحماية المقتنيات الفنية ( 1998 - 2000) من خلال تعاون بعض المعامل الوطنية في كل من إسبانيا، وبريطانيا، والسويد، وإيطاليا، والذي عني بتأثير هذا النظام علي الآفات الحشرية المختلفة - - المشروع الثاني، وهو ما يطلق عليه اختصارا DISIO حيث قام علي اشتراك عدد من المعامل الخاصة ببعض الجامعات والمعاهد البحثية لدراسة تأثير هذا النظام على الكائنات 
وكانت التوصية بالمطالبة بتعميم استخدام هذا النظام لمعالجة المقتنيات بالمكتبات والمتاحف وجميع مراكز حفظ التراث أن تكون 21 يومًا؛ لكي يتم التخلص من جمديع المديع الأطوار الحشرية بنسبة100\%.

\section{طريقة عمل جهاز ال Anoxia}

يتم سحب الهواء الجوي عن طريق Compressor ليتجمع في خزان للهواء الجوي والمكون

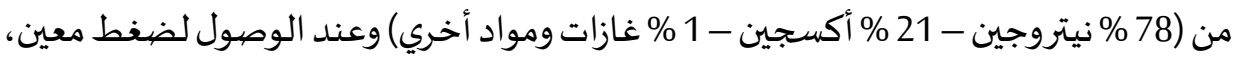

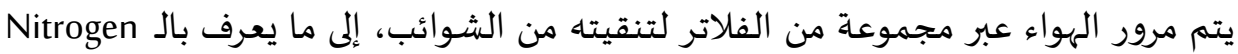
generator

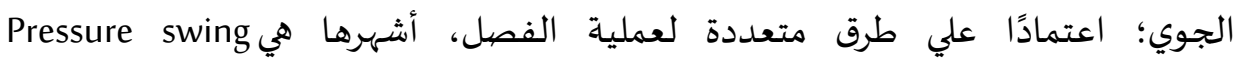

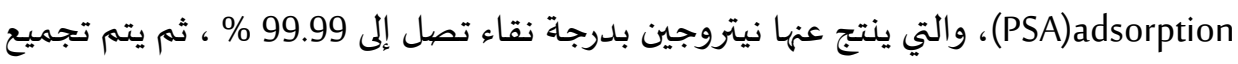

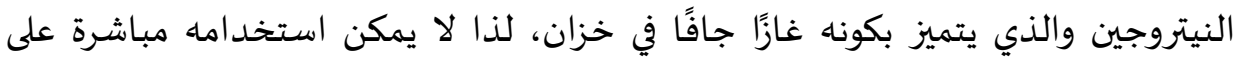

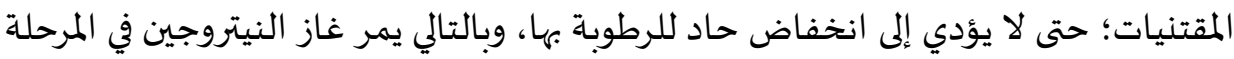

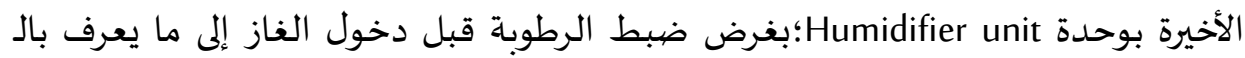
Bubble

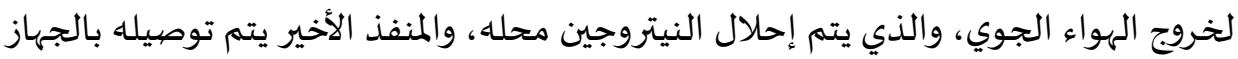

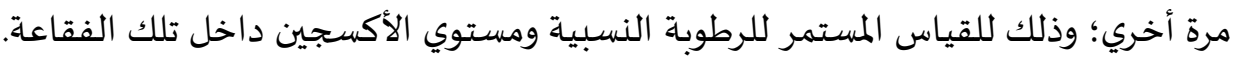

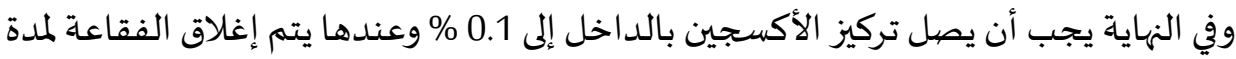

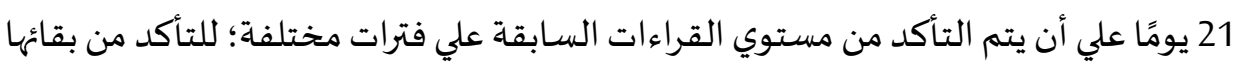

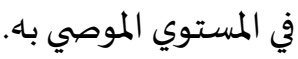



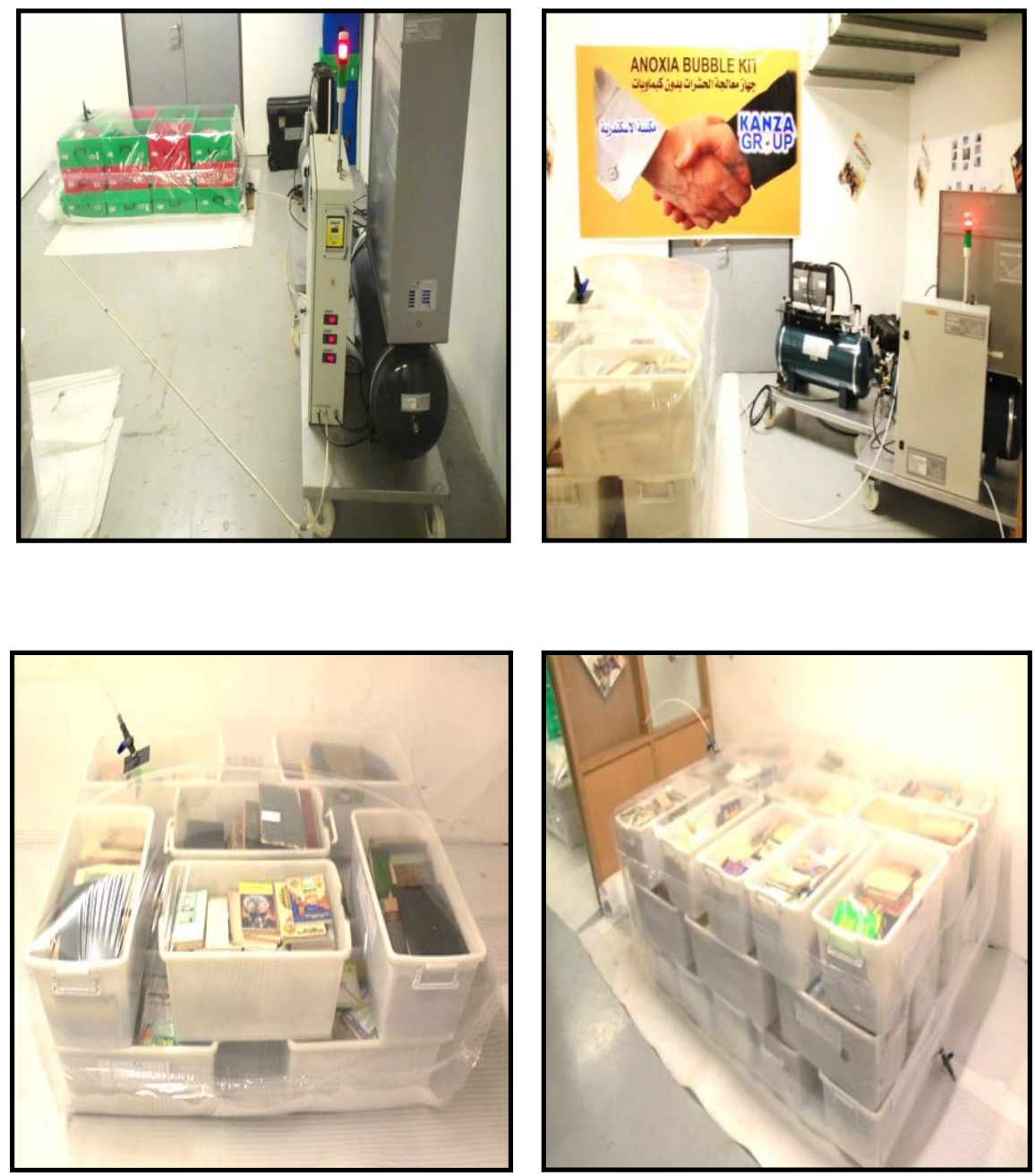

الشكل رقم ( 1) جهاز الأنوكسيا لمعالجـة وتعقيم الكتب بلدون مواد سـامة

"عيد زيدان رئليس قسم المكافحة ومعالجة الآفات المكتبية .مكتبة اسكندربة 2016"

Ultraviolet Radiation 5/2/3 الأشعة فوق البنفسجية

هي عبارة عن إشعاع كهرومغناطيسي من الطول الموجي يتراوح من 10-400 نانوميتر، ويستخدم في المجالات العلمية والصناعيةة، أما بالنسبة للتعقيم فيتكون في نطاق 260 نانوميتر؛ 
لأن هذا الطول الموجي يسبب تلفًا في جزيئات الحمض النووي ،وتسمى الأشعة فوق البنفسجية

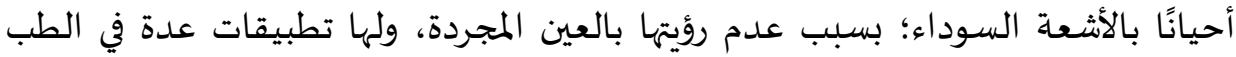
والإضاءة والكيمياء.

إن تعرض الكتب لأشعة الشمس المباشرة وفقا ل"s.sequeria Ibid)"Florian يعمل على

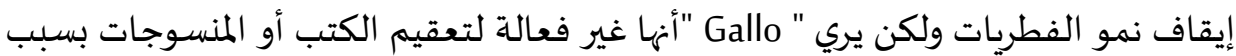
ضعف قوة الاختراق وتعمل الأشعة فوق البنفسجية على إحداث تلف في المواد الورقية كاصفرار

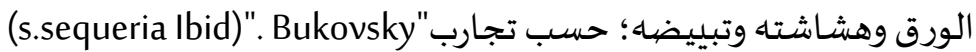

Temperature extremes 6/2/3 درجات الحرارة القصوي

Freezing التجميد-1/6/2/3

يستخدم التجميد لقتل الآفات الحشرية والحفاظ على الصور الفوتوغرافية؛ فهو مثل

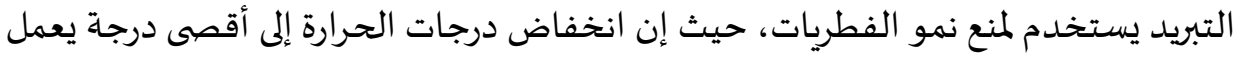

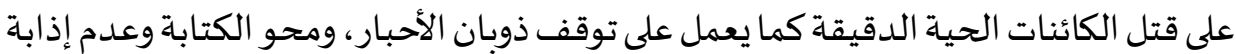

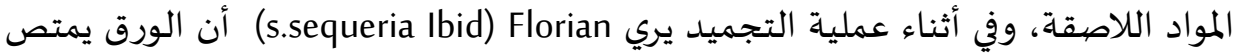

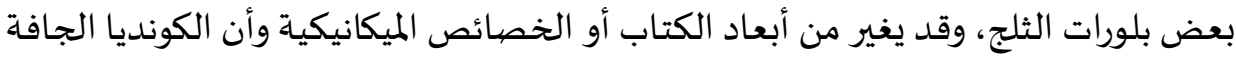

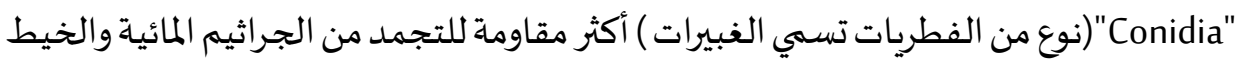

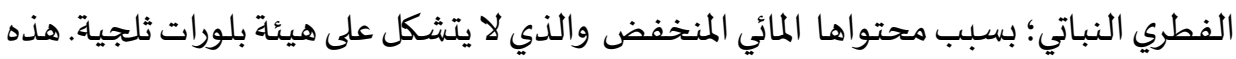

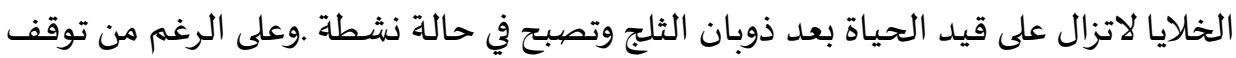

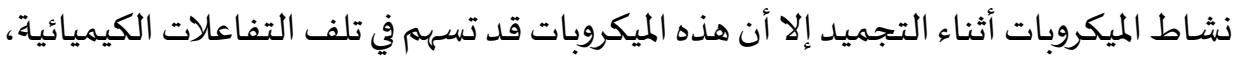

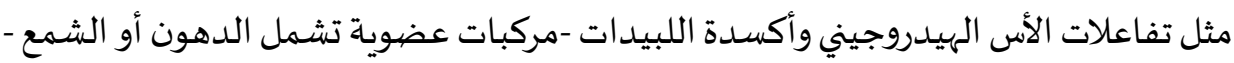

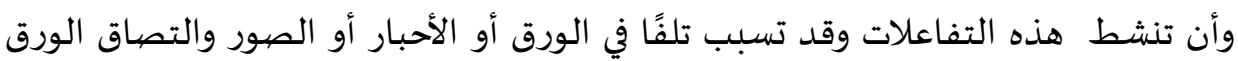

$$
\text { وإحداث تغيرات وتشوهات في الكتب. }
$$

وسائل آمنة أخري تطبيق طريقة التجميد في متحف المخطوطات بمكتبة الإسكندرية: في حالة الهجوم الحشري على المخطوطات أو الكتب النادرة، يتم التخلص منها عن طريق

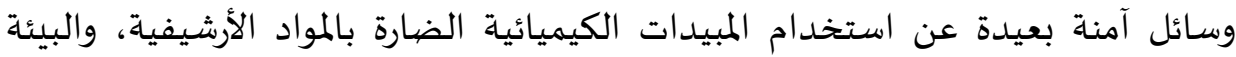


كالتجميد حتى (- 1) درجة في حضان خاص للقضاء علي جميع أشكال الحشرات بالمجموعات الأرشيفية.( حسام الديب 2018)

يرى المختصون في مكتبة الإسكندرية أن التجميد يقتل الحشرات عن طريق التغير

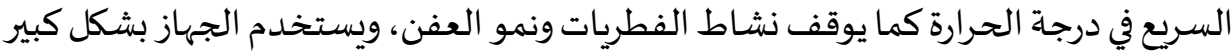

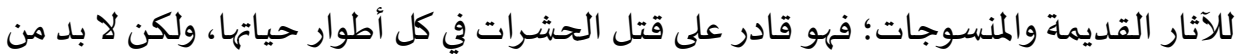

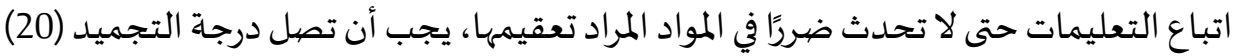
درجة مئوية أو أقل أي يجب أن يكون الجهاز قادر على الوصيول إلى درجة التجميد خلال 24

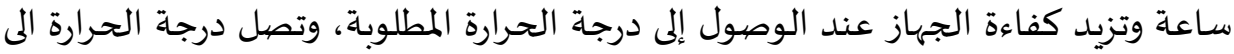

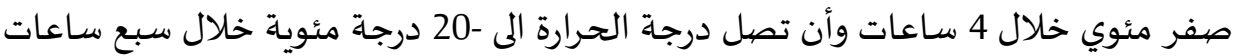
فقط

إذا تم إذابة التبريد ببطىء سوف تتأقلم الحشرات، ولن يتم القضياء عليها، وسوف تأخذ

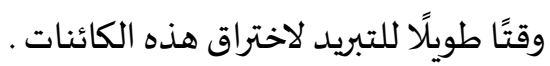
طريقة العمل: يتم وضع الكتب داخل أغلفة بلاستيكية من مادة البولي أثيلين قبل

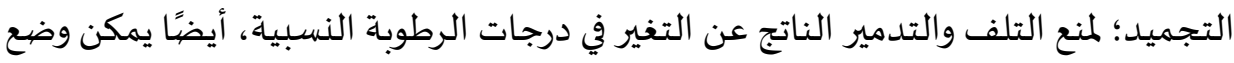

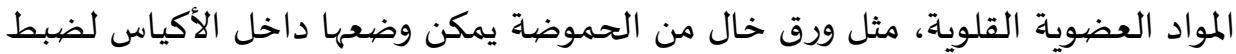
الرطوبة النسبية وامتصاصها.

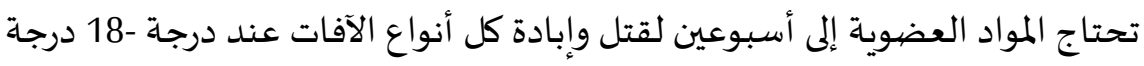

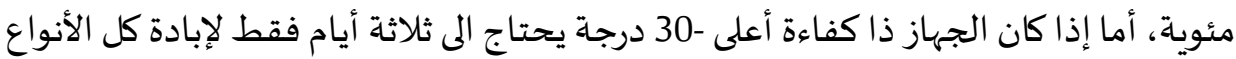

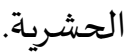

وعند إخراج الكتب من الجهاز يجب الحفاظ على الأغلفة حتى تصل الكتب إلى درجة

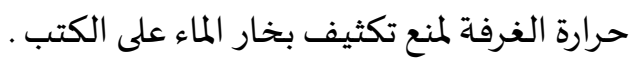

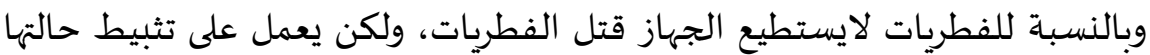

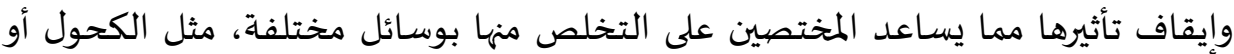
الأيزوبروبيل لا يستطيع الجهاز تعقيم الرق أو اللوحات الزيتية؛ حيث يغير من ملامحها ويحدث لها بعض التشوهات. 

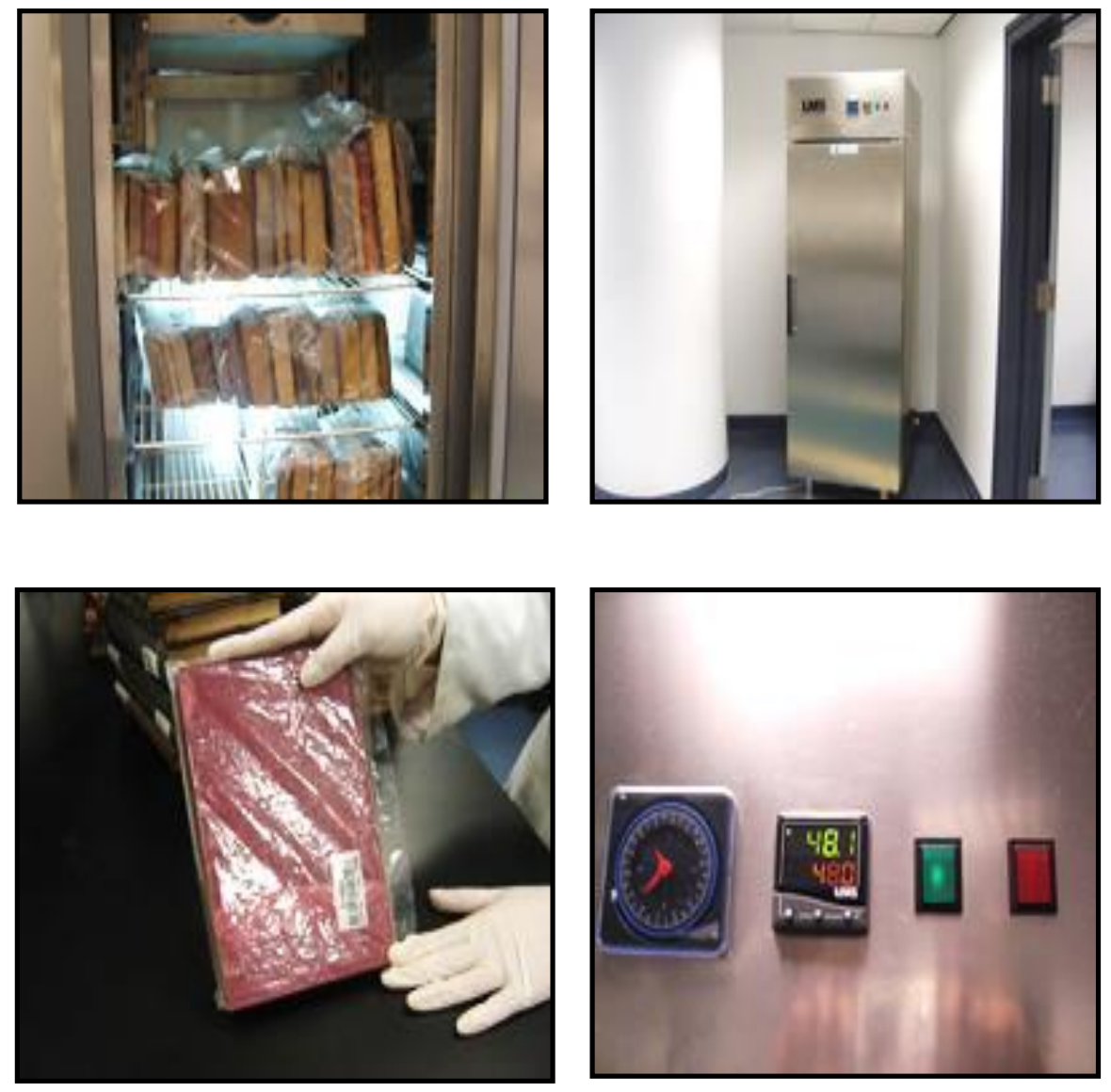

$$
\text { الشكل رقم (2) الحضيان الخاص لقتل الحشرات والفطريات }
$$

High temperature درجات الحرارة العالية 2/6/2/3

تعمل درجات الحرارة العالية على قتل الحشرات في درجات حرارة من 55-65 درجة لمدة

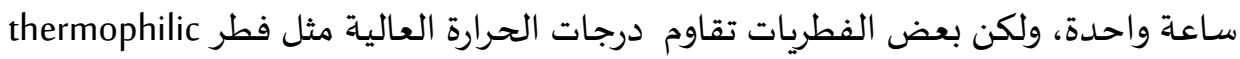

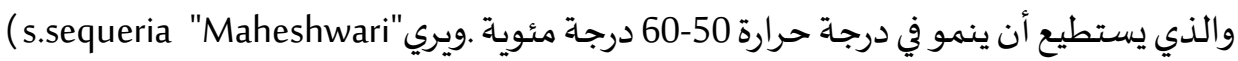

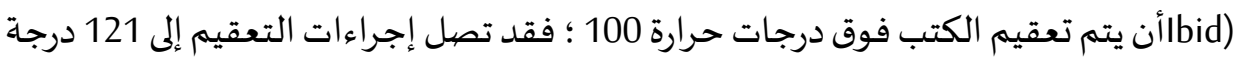
داخل حضانة مخصصية حتى تستطيع قتل الكائنات الدقيقة الجرثومية والأشكال النباتية، 
ولكن قد تسبب درجات الحرارة العالية تدهورًا في المواد الورقية واللواصق وقد تغير من حجم

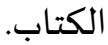

\section{الخاتمة}

الحفاظ على التراث الثقافي يساهم بشكل فعال في التعليم، والنهوض بالمعرفة، والسياحة، والاقتصاد، ويضمن أن تراثنا الثقافي يتم العناية باه وحمايته، والحفاظ علية لئلية لصالح الأجيال

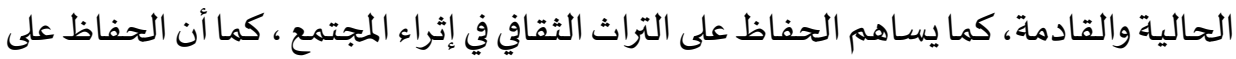

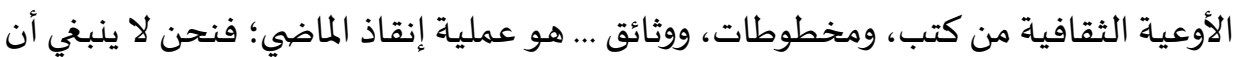
نفقد الماضي.

إن توعية العاملين بخطورة الكوارث المحتملة أمرًا في غاية الأهمية لأن التوعية ووضع خطة مكتوبة والتدريب المستمر للعاملين والمستفيدين عند حدوث أي كارثة سيعمل على تقليل

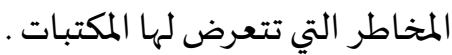

كما عرض هذا البحث بعض المواد التقليدية في التعقيم كيميائيًا وفيزيائيًا والمواد المستخدمة والتي أثرت بشكل مباشر على تلف الأوعية الثقافية وصحة العاملين، ولقد قدم البحث العلمي في نهاية القرن العشرين طرق حديثة في التعقيم مثل تقليل الأكسجين والتجميد

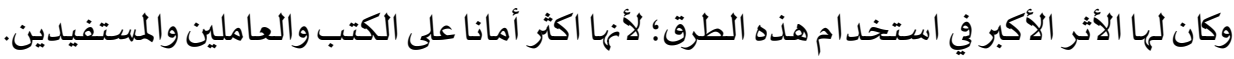




\section{المراجع}

\section{أولًا: المراجع باللغة العربية}

1- أدكوك، ب أدوارد،. (يوليو 2016). مبادئ الاتحاد الدولي لجمعيات ومؤسسات

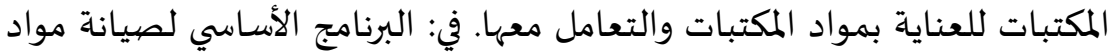
المكتبات والمحافظة عليها ومجلس المكتبات ومصيادر المعلومات. ترجمة مكتبة قطر. مكتبة قطر الوطنية . العدد(1).

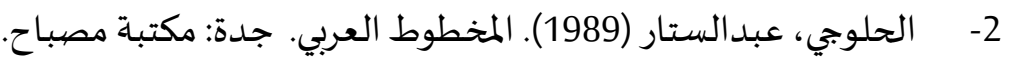
3- داغستاني، بسام (2002) المخطوط العربي الإسلامي حفظه معالجته وترميمها. دبي:

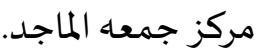
4- سمير، محمد وأخرون. (2017). الكيمياء للصف الثالث الثانوي. القاهرة :وزارة التربية والتعليم، مطبعة أكتوبر الهندسية.

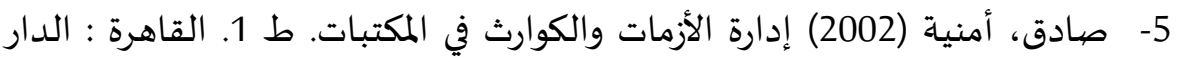

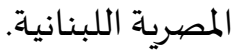
6- طله، يوسف ناصف(2016). متطلبات استكمال وترميم العناصر المعمارية المنحوتة

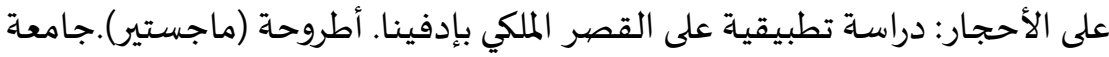
الإسكندرية. كلية الفنون الجميلة. 7- عبدالهادي، محمد (1997) دراسات علمية في ترميم وصيانة الآثار غير العضوية. القاهرة : مكتبة زهراء الشرق. 8- فرحات، أحمد. (2010). ورشـة عمل حول صيانة وترميم المخطوطات ـ ـ القاهرة: دار

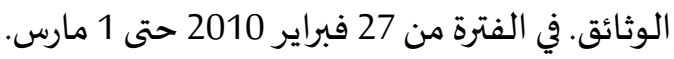

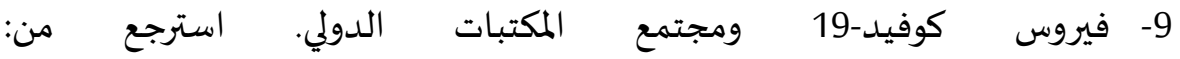
https://www.ifla.org/wp\%20\%20\%20\%20\%20\%20\%20\%20\%20\%20\%2 0\%20\%20content/uploads/2019/05/assets/hq/news/documents/covid-

19-resources-ar.pdf 
10- ماكلوين، جون. (2006). الوقاية من الكوارث والخطط الاستعجالية/ ترجمة كمال

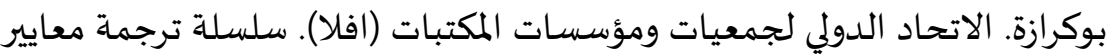

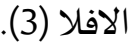

11- المبادئ التوجيهية للوقاية من الكوارث ومراقبتها. (2008)، المجلس الدولي للأرشيف

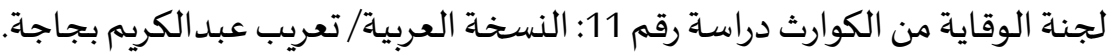
12- المزاحي، خالد (2016) واقع حفظ وصيانة وترميم مخطوطات مكتبة السيدة زينب. أطروحة (ماجستير). كلية الآاداب. جامعة الاسكندرية.

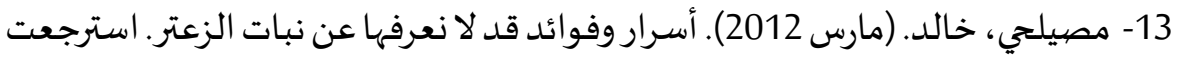

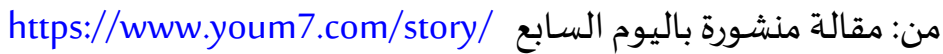

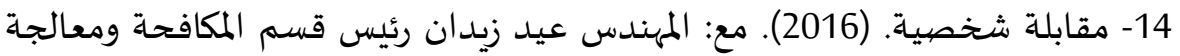
الآفات بمكتبة اسكندرياة. 15- مقابلة شخصيية. (2018). مع: الكيميائي حسام الديب رئيس قسم الحفاظ والضبط بـأ البيئي بمكتبة اسكندرية. 16- منصور، سميح. (2010). ورشة عمل حول صيانة وترميم المخطوطات ـ القاهرة: دار الوثائق. في الفترة من 27 فبراير 2010 حتى 1 مارس. 17- نوث، ربيكا. (2018). إبادة الكتب : تدمير الكتب والمكتبات برعاية الأنظمة السياسية

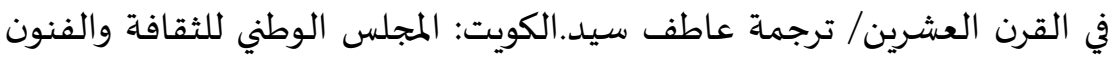

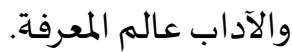
ثانيًا: المراجع باللغة الأجنبية

1- Adam Claude. (1991) Restauration des manuscrits et des livres rares Anciens. institute Francais de restauration des Oeuvres d art. Paris erec. Retrieved from: https://www.culturalheritage.org/about- conservation/what-is

2- Agarwal, B., Kumar, M., Agarwal, S., Singh, A., \& Shekhar, A. (2011). Bio medical waste and dentistry. Retrieved from: https://medicalwaste.org.ly/ 
3- Alkylating Agents. National Cancer Institute at the National Institutes of Health. Retrieved from: https://www.cancer.gov/publications/dictionaries/cancerterms/def/

4- Azole chemical compound antifungal drugs. Encyclopedia Britannica, Inc . Retrieved from: https://www.britannica.com/science/Azole

5- Conservation is about preventing damage and loss to our cultural heritage. Retrieved from: http://aiccm.org.au/conservation

6- conservation treatment. American Philosophical Society. Retrieved from: https://www.amphilsoc.org/conservation\#paragraph-77

7- Cuny, F. C. (1993). Introduction to disaster management: Lesson 2.Concepts and terms in disaster management. Prehospital and Disaster Medicine, 8(1), 89-95. Retrieved from: https://sac-elearning.com/courses/basics-of-disastermanagement/lesson/introduction-to-disaster-management-2

8- Dureau, Jeanne-Marie Principles of conservation and restoration of -collections in libraries Bulletin of the libraries of France (BBF).

9- Gamma Radiation. Retrieved from: https://www.arabsciencepedia.org/wiki/gama

10- Grau, Astrid Brandt. (2000). scientific coordination; Delvallée, Anne and Galard, François, realization; Roberts, Winston. IFLA, Safeguarding our documentary heritage: 2000 UNESCO CD.

11- Green, culture. (July 2011). Green Blog spot. Blog. Retrieved from: http://greens1.blogspot.com/2011/07/definition-of-green-culture.html

12- Guidelines for Preservation, Conservation, and Restoration of Local History and Local Genealogical Materials. RUSA: A division of American Library Association. Retrieved from:

https://www.ala.org./rusa/resources/guidelines/guidelinespreservation 
13- High-frequency current. 2008WordNet 3.0, Farlex clipart collection. (2003 2008). Retrieved from: https://www.thefreedictionary.com/

14- International Network for the conservation of contemporary. conservationhistoric-and-artistic-works-aic. Retrieved from: https://www.incca.org/articles/american-institute زيارة للتدريب على الترميم والتجليد بالمكتبة الوطنية الفرنسية من 1993حتى 1998.

15- Library of Congress. Retrieved from: https://www.wdl.org/ar/ Library of Congress

16- Linalool. Science Direct Books\& Journals. Retrieved from: https://www.sciencedirect.com/topics/medicine-and-dentistry/linalool

17- Lynn, Mary (1993) preserving archives and manuscripts, society of American archivists. Chicago.

18- National Center for Biotechnology Information (2021). PubChem Compound Summary for CID 18688743, CID 18688743. Retrieved from: https://pubchem.ncbi.nlm.nih.gov/compound/oxirane

19- O.Reilly, Naomi. Disaster Management. Retrieved from: https://www.physio pedia.com/Disaster_Management

20- Oddos, J. P., Brandt, A. C., Delcourt, T., Deschaux, J., Fages, B., Fossard, J. L., ... \& Varry, D. (1995). La conservation(principes et réalités). Bibliothèques.

21- Pearce-Moses, R., \& Baty, L. A. (2005). A glossary of archival and records terminology (Vol. 2013). Chicago, IL: Society of American Archivists. https://dictionary.archivists.org/entry/preservation.html

22- photocatalyst. (2003.) McGraw-Hill Dictionary of Scientific \& Technical Terms, 6E. Retrieved from: https://encyclopedia2.thefreedictionary.com/photocatalyst

23- PRESERVATION BASICS FOR PAPER AND MEDIA COLLECTIONS ONLINE TEXTBOOK. Retrieved from: https://www.nedcc.org/preservation101/ 
24- Rattan, P. (2013). Role of Library and Information Centers In Disaster Management. Library Philosophy and Practice (e-journal), 1-10. Retrieved from: $\underline{\text { https://digitalcommons.unl.edu/cgi/viewcontent.cgi?article=2204\&context=lib }}$ philprac

25- S. Sequeira. , E. J. Cabrita \& M.F. Macedo (2012). Antifungals on paper conservation: An overview. International Biodeterioration \& Biodegradation, 74. Retrieved from: https://www.elsevier.com/locate/ibiod

26- Salehioun, L., Azadi, M., Vahidzadeh, R., \& Taghipour, F. (2020). Determining the Effect of Preventive Conservation in Private Collections on the Cultural Values. Parseh Journal of Archaeological Studies, 4(13),193-205. Retrieved from: https://cool.conservation-us.org/waac/wn/wn18/wn18-2/wn18-202.html

27- Soete, Jeorge (2003), Library print preservation.an administrative briefing. Association of Research Libraries Washington, $\mathrm{D}$

28- Ten Reasons to preserve the library collections. Retrieved from: https://www.ala.org/alcts/sites/ala.org.alcts/files/content/confevents/preswk/ events/flyer.pdf

29- Terminology to characterize the conservation of tangible cultural heritage. Retrieved from: https://journals.openedition.org/ceroart/2794?file=

30- Terminology to characterize the conservation of tangible cultural heritage. Retrieved from: http:/www.icom-cc.org/242/about/terminology-forconservation/\#.YaEdyNBBxPY

31- World heritage. Retrieved from: http://www.unesco.org/ar/home/resourcesservices/faqs/ 